\title{
Pricing Strategies in Dual-Channel Supply Chain with a Fair Caring Retailer
}

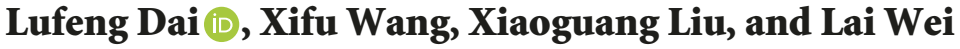 \\ School of Traffic and Transportation, Beijing Jiaotong University, Beijing, China \\ Correspondence should be addressed to Lufeng Dai; 15114213@bjtu.edu.cn
}

Received 11 September 2018; Revised 2 December 2018; Accepted 28 January 2019; Published 18 April 2019

Guest Editor: Ahmet Sensoy

Copyright (C) 2019 Lufeng Dai et al. This is an open access article distributed under the Creative Commons Attribution License, which permits unrestricted use, distribution, and reproduction in any medium, provided the original work is properly cited.

\begin{abstract}
Manufacturers add online direct channels that inevitably engage in channel competition with offline retail channels. Since price is an important factor in consumers' choice of purchasing channel, pricing strategy has become a popular topic for research on dual-channel competition and coordination. In contrast to previous research on pricing strategies based on the full rationality of members, we focus on the impact of retailers' fairness concerns on pricing strategies. In this study, the hybrid dual-channel supply chain consists of one manufacturer with a direct channel who acts as the leader and a retailer who acts as the follower. First, we use the Stackelberg game approach to determine the equilibrium pricing strategy for a fair caring retailer. Simultaneously, we consider a centralized dual-channel supply chain as the benchmark for a comparative analysis of the efficiency of a decentralized supply chain. Furthermore, we study pricing strategies when the retailer has fairness concerns and determine the complete equilibrium solutions for different ranges of the parameters representing cross-price sensitivity and fairness. Finally, through numerical experiments, the pricing strategies, the profit and utility of the manufacturer and retailer, and the channel efficiency of the supply chain are compared and analysed for two scenarios. We find that fairness concerns reduce the manufacturer's profits, while for the most part, the retailers' profit can be improved; however, the supply chain cannot achieve complete coordination.
\end{abstract}

\section{Introduction}

In recent years, the number of people who shop online has grown. Increasingly, manufacturers such as Lenovo, Dell, and Nike have added direct channels to increase their profitability. When a manufacturer sells through a traditional retailer and has a direct channel to consumers, it is called a dualchannel distribution system. In a dual-channel distribution system, the manufacturer and its retailers sell essentially the same products. Compared with traditional retail channels, online direct sales channels have lower operating costs, and consumers are given choices that provide them with more convenience and price discount (Takahashi K [1]). Supplydemand and competitive relationships coexist between the manufacturer and retailer after an online direct marketing channel opens. Competition may also lead to conflicts between the two channels in terms of cross-channel price and operations.

With the popularity of online shopping, the gaps between channels in some dual supply chains are narrowing as consumers have gradually adapted to the heterogeneity of channels and shopped more rationally. According to Accenture's Chinese consumer research report for 2018[2], preference of consumers for shopping online or going to stores is almost equal, particularly, smart digital consumers paying more attention to price comparison. China-ASEAN Mobile Internet Industry Alliance released a survey report on comparison of online and offline shopping behaviors of consumers for 2018 [3]. The report shows that the considered factors for consumers to choose online or offline shopping are basically the same. Especially when it comes to the products that consumers often buy online, such as cosmetics, clothing, electronic products, FMCG, etc., people tend to pay more attention to the price of products. The narrowing of channel differences means that different channels will cover the same customer groups and make the problem of channel price competition become more prominent.

A large number of investigations and studies have confirmed that firms, similar to individuals, have fairness preferences when they are treated unfairly in business (Rabin M [4]; 
Fehr E [5]; Kahneman D [6]; Kumar N [7]) and have shown that fairness concerns have a significant impact on decisionmaking. Compared with the traditional supply chain, the dual-channel supply chain easily occur unfair cooperation due to channel competition and other factors, which will lead to conflicts of interest and even the breakdown of cooperation. In order to increase sales, high-end liquor companies such as Yibin Wuliangye Group Company Ltd. have added online direct channels and offered discounted product on it (Dong Zhao [8]). The good market prospects of Chinese liquor make the liquor enterprises raise the wholesale price. Meanwhile, the liquor enterprises were trying to stabilize the offline retail price and limit the minimum selling price to maintain the brand image (Dong Zhao [8]; Chen Xing [9]). The impact of online direct selling and the passive situation of offline retail made some retailers feel that they have been treated unfairly and privately took the way of price-off promotions which destroyed the offline price system and damaged the interest of Wuliangye. Similar unfair phenomenon also happened in the cooperation between Gome and Gree Electric Appliances (Xuefei Zhong [10]). How should manufacturers coordinate channel conflicts by price strategies considering retailers' fairness concern.

This paper try to apply a fairness preference and the cross-price effect to the dual-channel supply chain decisionmaking model to obtain results and insights more in line with actual management practice. In this study, we consider a dual-channel supply chain where a manufacturer acts as the leader and a fair caring retailer is the follower in Stackelberg game and approach the complete equilibrium solutions of the supply chain members.

The remainder of this paper is organized as follows. In Section 2, we review dual-channel supply chain literatures related to pricing strategy and fairness. In Section 3, we develop the structure and demand functions of a dualchannel supply chain and discuss the model assumptions and describe the parameters. In Section 4, we discuss the equilibrium pricing strategies of the members when the retailer has no fairness concerns. In Section 5, we analyse the equilibrium pricing strategies of the manufacturer and a fair caring retailer. In Section 6, a numerical experiment is used to analyse the influence of fairness concerns and crossprice sensitivity on member decisions and supply chain performance. We conclude by presenting the equilibrium results and suggesting directions for future research in Section 7. All of the proofs are provided in Appendix.

\section{Literature Review}

Our paper is related to two streams of research: pricing strategy and fairness concern in the dual-channel supply chain.

2.1. Pricing Strategy Researches in Dual-Channel Supply Chain. Chiang et al. [11] showed that a vertically integrated online channel allows the manufacturer to constrain its retailer's pricing behavior in a dual-channel supply chain. Guo Yajun [12] showed that adding an online direct channel can expand the market, but it may also exacerbate channel conflicts and depress the retail price, leading to a loss in retailers' profit. Cattani et al. [13] studied the situation in which manufacturers adopt different pricing strategies in order to alleviate channel conflicts and found that reducing wholesale prices could alleviate the double margin effect and improve supply chain performance (Qing Fang [14]). Considering the dual-channel supply chain led by retailers and manufacturers, respectively, and making a comparative analysis of the optimal price decision, the dominant party will make the wholesale price beneficial to maximize its profit. Yan R [15] constructed the channel demand model based on consumer utility and studied the pricing strategy considering consumers have same price sensitivity of different channels. This paper found that channel conflict can be alleviated by price strategy after manufacturers encourage retailers to improve retail services. Based on the same channel price sensitivity of consumers, Tian J F [16] studied the pricing strategy when manufacturers develop retail service. With the development of dual-channel supply chain, some researchers have found that consumers have gradually adapted to the heterogeneity of channels, especially the products that consumers often buy online. Therefore, price comparison has become the focus of consumer attention. Xu et al. [17] analysed the price comparison behavior of consumers and its impact on decision-making and profit of supply chain members and found that the retailers and supplier are all more willing to avoid the existence of price comparison with the objective of profit maximization. Shen et al. [18] researched on the pricing strategy considering price comparison behavior and designed the corresponding coordination mechanism. To reduce channel conflict, Bo Li [19] considered a consistent pricing strategy in the two channels, which means that the price in the direct channel is equal to that in the retail channel. Zhang F [20,21] established the dynamic price game model and analysed the impact of price adjustment on the profit of supply chain members. Excessive price adjustment is often detrimental to their own interests but will make the other side to get more profits. Many scholars (e.g., [22-25]) have studied the price strategies for different channel structures and different product strategies.

The papers mentioned above have shown that price strategies play an important role in allocating channel profits and coordinating channel conflict. In dual-channel supply chain, price competition and channel conflicts may make members pay more attention to the distribution of profits; this paper make attempts to integrate members' fair preferences into pricing studies.

\subsection{Fairness Concern Researches in Dual-Channel Supply} Chain. Apart from the single-channel supply chain field, few scholars are engaged in applying fairness preferences to the dual-channel supply chain in their research (You Q et al. [26]; Guangxing Wei et al. [27]), among which Tengfei Nie and Shaofu Du [28], Qinghua Li and Bo Li[29], and Fang Z et al. [20] are the most representative. Reference [28] studied the application of a quantity discount contract in a dyadic supply chain consisting of one supplier and two retailers with no cross-price influence between channels. Retailers also 
focus on both horizontal and vertical fairness. This article determines the pricing strategies of the members of a supply chain when the fairness parameter differs. Further, it also introduces other coordination mechanisms to prove that the quantity discount contract cannot fully coordinate the supply chain. Reference [29] considered that the retailer provides value-added services, and they study the pricing decisions of the supply chain members for two scenarios: one in which the retailer has fairness concerns and a second in which it does not. The partial equilibrium solution of the channel quota is given in this article, but the complete equilibrium solution is not discussed. Reference [20] investigated two noncooperative dynamic game models: a Stackelberg game model and a vertical Nash game model. The paper used numerical experiments to analyse the influence of the retailer fairness preference on the dynamic behavior of supply chain members. The FS fairness model is simplified from using a piecewise function to using a continuous function to discuss how the retailer's behavior related to its fairness concerns influences member decisions and utility (Fujing Xu et al. [30]; Lei Wang et al. [31]; Bo Li et al. [32]).

In the aforementioned articles, there is a lack of attention to fairness concerns and cross-price sensitivity. Considering the influence of fairness concerns on strategy, only the local equilibrium solution of the members is inferred, and the complete process of the member's game cannot be fully understood based on this analysis. In practice, when the market environment and the level of fairness concerns of the members change, there are multiple equilibriums, which means that the members will adopt different strategies. Therefore, the complete equilibrium solutions and the corresponding management significance will become a focus of this paper.

\section{Problem Statement}

3.1. Model Assumption and Notation. w: per unit wholesale price of the manufacturer.

$p_{r}$ : per unit offline retail price of the retailer.

$p_{e}$ : per unit online direct price of the manufacturer.

$w^{n}$ : the superscript $\mathrm{n}$ takes the values of $d *$ and $f * *$, which denote the optimal wholesale pricing strategies with and without fairness concerns.

$p_{i}^{n}$ : the superscript $\mathrm{n}$ takes the values of $c *, d *$, and $f * *$, which denote the optimal strategies under the centralized and decentralized supply chain without fairness and the strategies considering fairness, respectively. The subscript $i$ takes the values of $r$ and $e$.

$a$ : the potential market demand of the channel.

$c$ : the manufacturer's marginal cost per unit.

$\theta$ : the cross-price sensitivity between channels.

$\alpha$ : a parameter reflecting the per unit difference in the payoffs of the manufacturer and the retailer when the retailer encounters disadvantageous unfairness.

$d_{r}$ : the demand function of the offline retail channel.

$d_{e}$ : the demand function of the online direct channel.

$\pi_{i}$ : the subscript $i$ takes the values of $c, d, m$, and $r$, which denote the total profit of both the centralized and

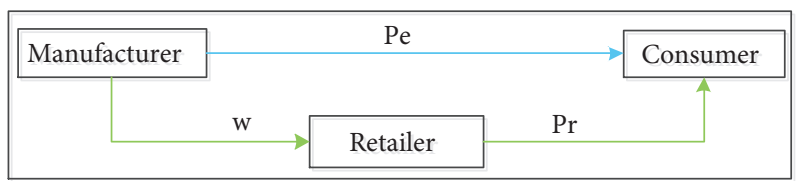

FIgURE 1: The dual-channel supply chain structure.

decentralized supply chains, the manufacturer's profit, and the retailer's profits without fairness concerns, respectively.

$\pi_{i}^{f}$ : the superscript $f$ denotes the scenario with fairness concerns; the subscript $i$ takes the values of $c, m$, and $r$, which denote the total profit of the supply chain, the manufacturer's profit, and the retailer's profit, respectively.

The following assumptions are made in our model. (1) The manufacturer and the retailer only sell one kind of product. (2) The potential share of both the online and offline channels is the same. (3) Information is symmetrical between the manufacture and the retailer. (4) The retailer is in a weak position.

\subsection{The Structure of the Dual-Channel Chain and Chan-} nel Demand Function. We consider a representative dualchannel structure in our study (see Figure 1). The supply chain consists of manufacturer $\mathrm{M}$ and retailer $\mathrm{R}$. The manufacturer creates infinitely divisible and homogeneous products and sells through both traditional offline retailers and online direct sales channels. We establish a Stackelberg game model to describe the problem between a rational manufacturer and a retailer with a fairness concern. The process of the game is as follows: the manufacturer, as the initiator of the game, first determines the online direct selling price $p_{e}$ and the wholesale price $w$; the retailer acts as the follower and then sets the offline retail price $p_{r}$.

Linear demand functions are used to characterize channel demand and have been adopted in studies (Yue X [33]; Huang $S$ [34]), and the corresponding demand functions to the manufacturer and the retailer are described as follows:

$$
\begin{aligned}
& d_{r}=a_{r}-b_{r} p_{r}+\theta p_{e}, \\
& d_{e}=a_{e}-b_{e} p_{e}+\theta p_{r}
\end{aligned}
$$

The differences in channel characteristics are mainly reflected in channel price elasticity $b$ and basic market demand of channel $a$. Subscript $r$ and $e$ represent the offline and online channels, respectively. Channel price elasticity depicts consumers' sensitivity to channel price. Basic market demand of channel reflects consumers' loyalty to the channel. When channel differences decrease, market characteristics corresponding to the original differentiated channels are gradually converging. Some scholars (Yan R [15]; Guangye $\mathrm{Xu}$ [35]) consider consumers have the same price sensitivity to different channels, but the channel loyalty is different. Channel loyalty of consumers is changing with the shopping habit. Research on China's digital consumers released by McKinsey Greater China in 2017 states that over 90\% of consumers compare online and offline channels when buying consumer electronics (Wei Wang [36]). According to a white 
paper on big data and online cosmetics consumption in 2016, although the growth rate of e-commerce has been slowing since 2012, the proportion of online and offline consumption is expected to be evenly divided into 2018 (Niuli [37]). Therefore, this paper considers a situation where the potential share of the channels is the same. Without loss of generality, we set parameter $b_{r}$ and $b_{e}$ to 1 , as were done in the studies ([23]; Liu M [38]). $\theta$ is the coefficient of cross-price sensitivity. The equation $0<\theta<1$ reflects the own-price effects, which are greater than the cross-price effects.

Obviously, it is necessary to impose additional inequity constraints on the parameters to guarantee the operation of the dual channels: (i) $p_{r} \geq w, p_{e} \geq w$. If $p_{e}<w$, then the retailer will find a less expensive source from the direct channel. (ii) $d_{e} \geq 0$ and $d_{r} \geq 0$, which ensures that every channel has sales. (iii) $w \geq c$.

\section{Pricing Strategy of Members When the Retailer Has No Fairness Concerns}

4.1. Equilibrium Analysis of the Centralized Supply Chain. To examine the efficiency of the decentralized supply chain both with and without fairness concerns, we consider a centralized dual-channel supply chain as a benchmark, where the manufacturer and the retailer are regarded as a vertically integrated supply chain system. The members make decisions to maximize the overall profit of the supply chain, and the wholesale price $w$ is no longer the decision variable in the centralized supply chain. The problem of the supply chain members is given as follows:

$$
\begin{aligned}
\max _{p_{r}, p_{e}} & \pi_{c}=d_{r}\left(p_{r}-c\right)+d_{e}\left(p_{e}-c\right) \\
\text { s.t } \quad p_{r} & \geq c \\
p_{e} & \geq c \\
d_{e} & \geq 0 \\
d_{r} & \geq 0 .
\end{aligned}
$$

By simultaneously solving the first-order conditions of the equations above for $p_{r}, p_{e}$, it can be shown that the Hessian matrix $H$ is negative definite. The optional channel price $p_{r}, p_{e}$ and the total profit of the supply chain are obtained.

$$
\begin{aligned}
p_{e}^{c *} & =p_{r}^{c *}=\frac{a}{2(1-\theta)}-\frac{c}{2}, \\
\pi_{c} & =\frac{(\theta c+a-c)^{2}}{2(1-\theta)} .
\end{aligned}
$$

In an integrated supply chain, the decision maker sets a uniform retail price for both online and offline sales to avoid channel competition. Obviously, with an increase in the cross-price sensitivity coefficient, the channel price increases, and the overall profit of the supply chain increases. In reality, enterprises often adopt the same price for the dual-channel, such as Suning, but a higher level of channel management is required in this situation (Chun Yuan et al. [39]).
4.2. Equilibrium Analysis of the Decentralized Supply Chain. In this section, we consider a decentralized dual-channel supply chain based on the assumption that neither party in the supply chain has fairness concerns and that both make decisions to maximize their individual profits.

4.2.1. The Retailer's Problem. Given the manufacturer's network direct selling price $p_{e}$ and wholesale price $w$, according to the previous game, the profit of the retailer is maximized as follows:

$$
\max _{p_{r}} \pi_{r}=d_{r}\left(p_{r}-w\right)
$$
follows:

The response function for the retailer can be described as

$$
p_{r}=\frac{a+w+\theta p_{e}}{2}
$$

4.2.2. The Manufacturer's Problem. The manufacturer's decision problem can be described as follows:

$$
\begin{aligned}
\max _{p_{e}, w} \pi_{m} & =d_{r}(w-c)+d_{e}\left(p_{e}-c\right) \\
\text { s.t } \quad p_{r} & =\frac{a+w+\theta p_{e}}{2}, \\
p_{e} & \geq w \\
d_{e} & \geq 0 \\
d_{r} & \geq 0 \\
w & >c .
\end{aligned}
$$

Therefore, the Hessian matrix of the manufacturer's profit function

$$
H_{\pi_{m}}\left[\begin{array}{c}
p_{e} \\
w
\end{array}\right]=\left[\begin{array}{cc}
\theta^{2}-2 & \theta \\
\theta & -1
\end{array}\right]
$$

is negatively definite. The manufacturer's profit function is a concave function of $p_{e}$ and $w$, and the decision problem is a convex optimization problem. Thus, a unique equilibrium solution exists. Therefore, we can deduce the optimal decision as follows:

$$
p_{e}^{d *}=w^{d *}=\frac{a}{2(1-\theta)}-\frac{c}{2}
$$

It is easy to prove (11) and satisfy (9). The optimal retail price is given by bringing (11) into (7):

$$
p_{r}^{*}=\frac{(3-\theta) a}{4(1-\theta)}+\frac{(1+\theta) c}{4}
$$


By bringing (11) and (12) into (6) and (8), we can obtain the profit of the manufacturer, the profit of the retailer, and the total profit of the supply chain as follows:

$$
\begin{aligned}
& \pi_{m}=\frac{(\theta+3)(\theta c+a-c)^{2}}{8(1-\theta)}, \\
& \pi_{r}=\frac{(\theta c+a-c)^{2}}{16}, \\
& \pi_{d}=\frac{(\theta c+a-c)^{2}(\theta+7)}{16(1-\theta)} .
\end{aligned}
$$

By analysing the inferred strategies and profits, we find the following: the channel efficiency $\left(\pi_{d} / \pi_{c}=(\theta+7) / 8\right)$ of the decentralized supply chain is an increasing function of the cross-price coefficient $\theta$, which indicates that the double marginalization will be weakened when $\theta$ increases. Similarly, we can draw the same conclusion from the equilibrium pricing strategy. The cross-price sensitivity coefficient has a positive impact on the channel price. As $\theta$ increases (see (11) and (12)), both the manufacturer and the retailer will use a higher pricing strategy to improve its profits, which increases the overall profit of the supply chain.

\section{Pricing Strategy of Members When the Retailer Has Fairness Concerns}

The supply chain cannot be coordinated when the retailer does not have a fairness concern. However, it is necessary to determine how the strategy changes when we consider the effect of fairness concerns and whether channel efficiency could be improved. These issues are discussed in the following section.

5.1. The Retailer's Problem. Because we consider the fairness concerns of the retailer in the distribution of profits, we must establish a model for fairness concerns. Some may argue that a more general model that includes both aversion to disadvantageous inequality and aversion to advantageous inequality (for example, Fehr and Schmidt [5] and Charness
\& Rabin [40]) is more desirable. However, a preference for advantageous inequality is much less prominent (Loewenstein, Thompson, and Bazerman [41] did not find it in their experiment $\mathrm{Ho} \& \mathrm{Su}[42])$. Furthermore, we assume that the retailer's fairness reference is the manufacturer's profit $\pi_{s . r}$ instead of $\gamma \pi_{s . r}(\gamma>0)$ because the general setting will not produce substantially different or more insightful results than a simple setting with $\gamma=1$ (Pavlov \& Katok [43]; Tengfei Nie and Shaofu Du [28]). The utility function of the retailer can be written as follows:

$$
U_{r}=\pi_{r}-\alpha\left(\pi_{m . r}-\pi_{r}\right)^{+},
$$

where $\pi_{r}=d_{r}\left(p_{r}-w\right)$ denotes the retailer's monetary payoff, $\pi_{m, r}=d_{r}(w-c)$ denotes the profits of the manufacturer's offline channel, and $\alpha$ denotes the level of the retailer's fairness concern about the distribution of offline profits, as retailers pay more attention to the profits made by manufacturers from offline channels and compare them to the profits made from the online channel. If the retailer's monetary profit is lower than the equitable profit $\pi_{m \cdot r}-\pi_{r} \geq 0$, disadvantageous inequality occurs. By contrast, if $\pi_{m . r}-\pi_{r}<$ 0 , then $U_{r}=\pi_{r}$, which indicates that the retailer's utility function is equal to the profit function.

When the retailer faces disadvantage inequality, its decision problem is

$$
\begin{aligned}
\max _{p_{r}} & U_{r}=(1+\alpha) d_{r}\left(p_{r}-w\right)-d_{r}(w-c) \\
\text { s.t } & p_{r} \leq 2 w-c
\end{aligned}
$$

The decision of the retailer is

$$
\begin{aligned}
& p_{r}^{f} \\
& = \begin{cases}\frac{w(2 \alpha+1)}{2(\alpha+1)}+\frac{\theta p_{e}}{2}-\frac{a+\alpha(a-c)}{2(\alpha+1)} & \text { if } p_{e}<K_{1} w-D_{1} \\
2 w-c & \text { if } p_{e} \geq K_{1} w-D_{1}\end{cases}
\end{aligned}
$$

where $K_{1}=(2 \alpha+3) / \theta(\alpha+1) ; D_{1}=(\alpha+2) c / \theta(\alpha+1)+a / \theta$. The corresponding utility of the retailer is

$$
U_{r}= \begin{cases}\frac{\left(b(\alpha+1) p_{e}-(2 \alpha+1) w+(\alpha+1) a+\alpha c\right)^{2}}{4(\alpha+1)} & \text { if } p_{e}<K_{1} w-D_{1} \\ (w-c)\left(\theta p_{e}-2 w+a+c\right) & \text { if } p_{e} \geq K_{1} w-D_{1}\end{cases}
$$

When the retailer is faced with advantageous inequality, its decision problem is

$$
\begin{aligned}
\max _{p_{r}} & U_{r}=(1+\alpha) d_{r}\left(p_{r}-w\right)-d_{r}(w-c) \\
\text { s.t } & p_{r}>2 w-c
\end{aligned}
$$

The decision of the retailer is

$$
p_{r}^{f}= \begin{cases}\frac{\theta p_{e}+w+a}{2} & \text { if } p_{e}>K_{2} w-D_{2} \\ 2 w-c & \text { if } p_{e} \leq K_{2} w-D_{2}\end{cases}
$$

where $K_{2}=3 / \theta ; D_{2}=(a+2 c) / \theta$.

The corresponding utility of the retailer is

$U_{r}$ 


$$
= \begin{cases}\frac{1}{4}\left(a-w+\theta p_{e}\right)^{2} & \text { if } p_{e}>K_{2} w-D_{1} \\ (w-c)\left(\theta p_{e}-2 w+a+c\right) & \text { if } p_{e} \leq K_{2} w-D_{1} .\end{cases}
$$

$$
\begin{aligned}
& p_{r}^{f}= \begin{cases}\frac{\theta p_{e}+w+a}{2} & \text { if } p_{e}>K_{2} w-D_{2} \\
2 w-c & \text { if } K_{1} w-D_{1} \leq p_{e} \leq K_{2} w-D_{2} \\
\frac{w(2 \alpha+1)}{2(\alpha+1)}+\frac{\theta p_{e}}{2}-\frac{a+\alpha(a-c)}{2(\alpha+1)} & \text { if } p_{e}<K_{1} w-D_{1}\end{cases} \\
& U_{r}= \begin{cases}\frac{1}{4}\left(a-w+\theta p_{e}\right)^{2} & \text { if } p_{e}>K_{2} w-D_{1} \\
(w-c)\left(\theta p_{e}-2 w+a+c\right) & \text { if } K_{1} w-D_{1} \leq p_{e} \leq K_{2} w-D_{1} \\
\frac{\left(b(\alpha+1) p_{e}-(2 \alpha+1) w+(\alpha+1) a+\alpha c\right)^{2}}{4(\alpha+1)} & \text { if } p_{e}<K_{1} w-D_{1} .\end{cases}
\end{aligned}
$$

5.2. The Manufacturer's Problem. We divide the feasible region of the manufacturer's strategies to obtain the equilibrium solutions. By substituting (12) into $d_{e} \geq 0, d_{r} \geq 0$, and summarizing other conditions $\left(p_{e} \geq w, w>c\right.$, and the fairness boundary condition), we can confirm the feasible region as shown in Figure 2.

The feasible region consists of R1, R2, and R3. R1 and $\mathrm{R} 3$ denote the feasible region of the manufacturer's strategy when the retailer faces both disadvantageous inequality and advantageous inequality. Therefore, $\mathrm{R} 2$ denotes the feasible region when the retailer obtains a fair distribution of the profits. The expressions for the boundary conditions are summarized in Table 1.

It is easy to prove that R2 and R3 satisfy the constraint $\left(d_{r}>0\right)$. Considering the response functions of the different regions, we can solve the partial equilibrium strategies of the manufacturer accordingly. Then, we can obtain the optional solutions $\left(w^{f * *}, p_{e}^{f * *}\right)$ by comparing the partial equilibrium strategies of the different regions.

In $R 1$, we denote $\left(w_{1}^{f}, p_{e, 1}^{f}\right)$ as the partial equilibrium strategies and $\pi_{m 1}^{f}$ as the optimal profit of the manufacturer. The optimal model is as follows:

$$
\begin{array}{ll}
\max _{p_{e}, w} & \pi_{m 1}^{f}=d_{e}\left(p_{e}-c\right)+d_{r}(w-c) . \\
\text { s.t. } & p_{r}=\frac{w(2 \alpha+1)}{2(\alpha+1)}+\frac{\theta p_{e}}{2}+\frac{a+\alpha(a-c)}{2(\alpha+1)}, \\
& p_{e}<K_{1} w-D_{1}, \\
& p_{e} \geq K_{3} w-D_{3}, \\
& p_{e}>K_{4} w-D_{4}, \\
& p_{e}<K_{5} w-D_{5} .
\end{array}
$$

In $\mathrm{R} 2$, we denote $\left(w_{2}^{f}, p_{e, 2}^{f}\right)$ as the partial equilibrium strategies and $\pi_{m 2}^{f}$ as their optimal profit. The optimal model is as follows:

$$
\begin{array}{ll}
\max _{p_{e}, w} & \pi_{m 2}^{f}=d_{e}\left(p_{e}-c\right)+d_{r}(w-c) \\
\text { s.t. } & p_{r}=2 w-c, \\
& p_{e} \geq K_{1} w-D_{1}, \\
& p_{e} \leq K_{2} w-D_{2}, \\
& p_{e}>K_{3} w-D_{3}, \\
& p_{e} \leq K_{6} w-D_{6} .
\end{array}
$$

In $\mathrm{R} 3$, we denote $\left(w_{3}^{f}, p_{e, 3}^{f}\right)$ as the partial equilibrium strategies, and $\pi_{m 3}^{f}$ denotes the optimal profit for the manufacturer as follows:

$$
\begin{array}{ll}
\max _{p_{e}, w} & \pi_{m 3}^{f}=d_{e}\left(p_{e}-c\right)+d_{r}(w-c) . \\
\text { s.t. } & p_{r}=\frac{\theta p_{e}+w+a}{2} \\
& p_{e} \geq K_{2} w-D_{2} \\
& p_{e} \geq K_{3} w-D_{3} \\
& p_{e} \leq K_{7} w-D_{7} \\
& w>c .
\end{array}
$$

Therefore, the optimal profit from the decisionmaking problem for the manufacturer is $\max \pi_{m}^{f *}=$ $\max \left\{\pi_{m 1}^{f}, \pi_{m 2}^{f}, \pi_{m 3}^{f}\right\}$. Thus, we denote $\left(w^{f * *}, p_{e}^{f * *}\right)$ as the global optimal solution, which is referred to as an equilibrium strategy in the following. By substituting $\left(w^{f * *}, p_{e}^{f * *}\right)$ into (23), we can deduce the optimal retail price $p_{r}^{f}$. Furthermore, 
TABLE 1: Boundary conditions of the feasible region.

\begin{tabular}{lcc}
\hline & Expressions for boundary conditions & Meaning \\
\hline L1 & $p_{e}=\frac{(2 \alpha+3)}{\theta(\alpha+1)} w-\frac{(\alpha+2) c}{\theta(\alpha+1)}-\frac{a}{\theta}$ & $\begin{array}{c}\text { Fairness } \\
\text { condition }\end{array}$ \\
\hline $\mathrm{L} 2$ & $p_{e}=\frac{3}{\theta}-\frac{a+2 c}{\theta}$ & $\begin{array}{c}\text { Fairness } \\
\text { condition }\end{array}$ \\
\hline $\mathrm{L} 3$ & $p_{e}=w$ & $\begin{array}{c}\text { Foundation } \\
\text { boundary }\end{array}$ \\
\hline $\mathrm{L} 4$ & $p_{e}=\frac{(2 \alpha+1) w}{\theta(\alpha+1)}-\frac{a}{\theta}-\frac{\alpha c}{\theta(\alpha+1)}$ & $\mathrm{R} 1: d_{r}=0$ \\
\hline $\mathrm{L} 5$ & $p_{e}=\frac{(2 \alpha+1) \theta w}{\left(2-\theta^{2}\right)(\alpha+1)}+\frac{(2+\theta) a}{2-\theta^{2}}-\frac{\alpha \theta c}{\left(2-\theta^{2}\right)(\alpha+1)}$ & $\mathrm{R} 1: d_{e}=0$ \\
\hline $\mathrm{L} 6$ & $p_{e}=\frac{(3 \alpha+2) \theta w}{2\left(2-\theta^{2}\right)(\alpha+1)}+\frac{(\alpha+1)(\theta+2) a-\left((\alpha+1)\left(\theta^{2}+\theta-2\right)+\alpha \theta\right) c}{2\left(2-\theta^{2}\right)(\alpha+1)}$ & $\mathrm{R} 2: d_{e}=0$ \\
\hline $\mathrm{L} 7$ & $p_{e}=\frac{\theta w}{2-\theta^{2}}+\frac{(\theta+2) a}{2-\theta^{2}}$ & $\mathrm{R} 3: d_{e}=0$ \\
\hline
\end{tabular}

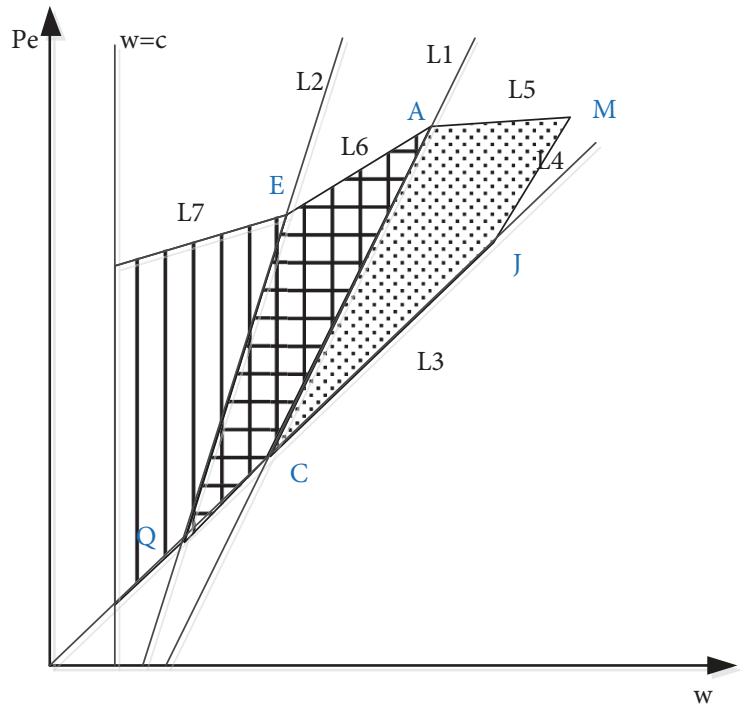

$\therefore \because \mathrm{R} 1$

田1 R2

$\square[1 \square$ R3

FiguRE 2: The feasible region of the manufacturer's strategies.

TABLE 2: The partial equilibrium strategies of the manufacturer in R1.

\begin{tabular}{lccccc}
\hline$\alpha$ & \multicolumn{2}{c}{$\left(0, \alpha_{1}\right]$} & \multicolumn{3}{c}{$\left(\alpha_{1}, 1\right)$} \\
\hline$\theta$ & $\left(0, \bar{\theta}_{3}\right]$ & $\left(\bar{\theta}_{3}, 1\right)$ & $\left(0, \bar{\theta}_{2}\right]$ & $\left(\bar{\theta}_{2}, \bar{\theta}_{3}\right]$ & $\left(\bar{\theta}_{3}, 1\right)$ \\
\hline$w_{1}^{f f}$ & $w_{1}^{f *}$ & $\bar{w}_{1,4}^{f *}$ & $\bar{w}_{1,3}^{f *}$ & $w_{1}^{f *}$ & $\bar{w}_{1,4}^{f *}$ \\
\hline$p_{e, 1}^{f f}$ & $p_{e, 1}^{f *}$ & $\bar{p}_{e 1,4}^{f *}$ & $\bar{p}_{e 1,3}^{f *}$ & $p_{e, 1}^{f *}$ & $\bar{p}_{e 1,4}^{f *}$ \\
\hline
\end{tabular}

we can obtain the optimal profit and utility of the retailer as well as the profit of the manufacturer.

First, we discuss the pricing strategies of R1, R2, and R3 (hereinafter referred to as "partial equilibrium strategies"). $\left(w_{i}^{f *}, p_{e, i}^{f *}\right), i=1,2,3$, denotes the extreme point in region
TABLE 3: The partial equilibrium strategies of the manufacturer in R2.

\begin{tabular}{lccc}
\hline$\theta$ & $\left(0, \bar{\theta}_{6}\right]$ & $\left(\bar{\theta}_{6}, \bar{\theta}_{5}\right]$ & $\left(\bar{\theta}_{5}, 1\right)$ \\
\hline$w_{2}^{f}$ & $\bar{w}_{2,2}^{f *}$ & $w_{2}^{f *}$ & $\bar{w}_{2,1}^{f *}$ \\
\hline$p_{e, 2}^{f *}$ & $\bar{p}_{e 2,2}^{f *}$ & $p_{e, 2}^{f *}$ & $\bar{p}_{e 2,1}^{f *}$ \\
\hline
\end{tabular}

i. $\left(\bar{w}_{i, j}^{f *}, \bar{p}_{e, i, j}^{f *}\right)$ denotes the maximum point on boundary $j$ in region $i$.

Lemma 2. In R1, the partial equilibrium strategies of the manufacturer are shown in Table 2.

Appendix A provides the proof of Lemma 2, the analytical expressions of all partial equilibrium strategies and the thresholds of the parameters.

Similarly, we provide the optional solutions for R2 and R3 in Lemmas 3 and 4.

Lemma 3. In R2, the partial equilibrium strategies of the manufacturer are shown in Table 3.

Appendix B provides the proof of Lemma 3, the analytical expressions of all partial equilibrium strategies, and the thresholds of the parameters.

Lemma 4. In R3, the partial equilibrium strategy of the manufacturer is shown as follows:

$$
\left(w_{3}^{f}, p_{e, 3}^{f}\right)=\left(\bar{w}_{3,2}^{f *}, \bar{p}_{e 3,2}^{f *}\right)=\left(\bar{w}_{2,2}^{f *}, \bar{p}_{e 2,2}^{f *}\right)
$$

The partial equilibrium strategy of the manufacturer in R3 $\left(\bar{w}_{3,2}^{f *}, \bar{p}_{e 3,2}^{f *}\right)$ is equal to the partial $\left(0<\theta \leq \bar{\theta}_{6}\right)$ solution of R2 $\left(\bar{w}_{2,2}^{f *}, \bar{p}_{e 2,2}^{f *}\right)$, which proves that there is no partial equilibrium strategy in R3. We can also obtain the same conclusion through the following analysis. The retailer will decide $p_{r}^{f}=$ $2 w-c$ rather than $p_{r}^{f}=\left(\theta p_{e}+w+a\right) / 2$ because of the fairness concern when the manufacturer adopts the optimal pricing strategy $\left(w_{3}^{f *}, p_{e, 3}^{f *}\right)$, which reduces the profit of the manufacturer. Thus, the manufacturer will adopt strategy 
TABLE 4: The complete equilibrium strategy of the manufacturer.

\begin{tabular}{|c|c|c|c|c|c|}
\hline \multicolumn{4}{|c|}{ Parameter range } & \multicolumn{2}{|c|}{ Equilibrium strategy } \\
\hline$\theta$ & $\alpha$ & $\theta$ & $\alpha$ & $w^{f * *}$ & $p_{e}^{f * *}$ \\
\hline \multirow{6}{*}{$0<\theta \leq \bar{\theta}_{6}$} & $0<\alpha \leq \alpha_{1}$ & $0<\theta \leq \bar{\theta}_{7}$ & $\begin{array}{c}0<\alpha \leq \alpha_{2} \\
\alpha_{2}<\alpha \leq \alpha_{1}\end{array}$ & $\begin{array}{l}w_{1}^{f *} \\
\bar{w}_{2,2}^{f *}\end{array}$ & $\begin{array}{c}p_{e, 1}^{f *} \\
\bar{p}_{e, 2,2}^{f *}\end{array}$ \\
\hline & & $\bar{\theta}_{6}<\theta \leq \bar{\theta}_{7}$ & $0<\alpha \leq \alpha_{1}$ & $w_{1}^{f *}$ & $p_{e, 1}^{f *}$ \\
\hline & & $0<\theta \leq \bar{\theta}_{2}$ & $\alpha_{1}<\alpha<1$ & $\bar{w}_{2,2}^{f *}$ & $\bar{p}_{e, 2,2}^{f *}$ \\
\hline & $\alpha_{1}<\alpha<1$ & $\bar{\theta}_{2}<\theta \leq \bar{\theta}_{7}$ & $\alpha_{1}<\alpha<1$ & $\bar{w}_{2,2}^{f *}$ & $\bar{p}_{e, 2,2}^{f *}$ \\
\hline & $\omega_{1}<a_{1}=1$ & $\bar{\theta}_{7}<\theta \leq \bar{\theta}_{6}$ & $\alpha_{1}<\alpha \leq \alpha_{2}$ & $\begin{array}{l}w_{1}^{f *} \\
\bar{w}^{f *}\end{array}$ & $\begin{array}{l}p_{e, 1}^{f *} \\
p_{f *}\end{array}$ \\
\hline & & & $\alpha_{2}<\alpha<1$ & $\bar{w}_{2,2}^{\prime *}$ & $\bar{p}_{e, 2,2}^{j *}$ \\
\hline \multirow{3}{*}{$\bar{\theta}_{6}<\theta \leq \bar{\theta}_{5}$} & & & $0<\alpha \leq \alpha_{3}$ & $w_{1}^{f *}$ & $p_{e, 1}^{f *}$ \\
\hline & $0<\alpha<1$ & $\theta_{6}<\theta \leq \theta_{8}$ & $\alpha_{3}<\alpha<1$ & $w_{2}^{f *}$ & $p_{e, 2}^{f *}$ \\
\hline & & $\bar{\theta}_{8}<\theta \leq \bar{\theta}_{5}$ & $0<\alpha<1$ & $w_{1}^{f *}$ & $p_{e, 1}^{f *}$ \\
\hline $\bar{\theta}_{5}<\theta \leq \bar{\theta}_{3}$ & $0<\alpha<1$ & $\bar{\theta}_{5}<\theta \leq \bar{\theta}_{3}$ & $0<\alpha<1$ & $w_{1}^{f *}$ & $p_{e, 1}^{f *}$ \\
\hline $\bar{\theta}_{3}<\theta<1$ & $0<\alpha<1$ & $\bar{\theta}_{3}<\theta<1$ & $0<\alpha<1$ & $\bar{w}_{1,4}^{f *}$ & $\bar{p}_{e, 1,4}^{f *}$ \\
\hline
\end{tabular}

$\left(\bar{w}_{2,2}^{f *}, \bar{p}_{e 2,2}^{f *}\right)$ rather than $\left(w_{3}^{f *}, p_{e, 3}^{f *}\right)$ after considering the situation. This phenomenon also reflects the diversity of the impact of fairness concerns on the member's decisionmaking.

Appendix C provides the proof of Lemma 4.

Proposition 5. By comparing the partial equilibrium strategies of R1-R3, we can determine the complete equilibrium strategies, as shown in Table 4.

Appendix D provides the proof of Proposition 5, the analytical expressions of all partial equilibrium strategies, and the thresholds of the parameters.

Note that $\theta$ and $\alpha$ codivide the manufacturer's final decision space in Table 4 . The complete equilibrium solution is composed of four pricing strategies of the manufacturer and the retailer. Additionally, there are some remarkable phenomena. (1) The manufacturer does not adopt the pricing strategy in R3, which is illustrated in Lemma 4. (2) When the cross-price sensitivity coefficient exceeds a threshold $\bar{\theta}_{3}$, the pricing strategy of the manufacturer makes the offline sales volume too small, and the manufacturer may choose to cancel the offline retail channel at this time.

The expressions of the optimal solutions are complex; therefore, the analysis of Proposition 5 is supported by numerical examples in the next section. In addition, all of the thresholds for $\theta$ and $\alpha$ are analytic expressions; therefore, the influence of the parameters on the members' decisions and supply chain efficiency is analysed by selecting parameters that are representative of a real-life situation.

\section{Numerical Analysis}

In this section, using numerical experiments, we provide additional management implications to prove the propositions discussed above. The analysis is conducted as follows: we analyse the impacts of the retailer's fairness concerns and cross-price sensitivity on the pricing strategies and the profits and utility of the two members in different settings. In particular, we focus on the impact of the influencing factor on the variations in channel efficiency when the members change their strategies.

As this paper mainly studies the influence of fairness concerns on dual-channel decision-making, several reference values are set for the cross-price sensitivity coefficient, and an interval simulation is conducted for the fairness concern, where $\alpha$ varies from 0 to 1 . We employ data based on a comparison of previous studies $([23,29])$. The cross-price sensitivity coefficient is set to 0.3 and 0.5 , which means that the coefficient is normal and high, respectively. The other basic parameters in the experiments are set as follows: $a=1$ and $c=0.3$. The constraint problem is no longer considered, as the complete equilibrium solution satisfies the constraint conditions in the proof. The experimental results are shown in Figures 3-7.

Observation 6 (change in equilibrium strategy).

(1) Effects of $\theta$ and $\alpha$ on Pricing Strategy. As $\alpha$ changes, the manufacturer develops two strategies considering a fair caring retailer, as shown in Figures 3 and 4. For convenience, $\left(p_{r, 1}^{f *}, w_{1}^{f *}, p_{e, 1}^{f *}\right)$ is referred to as equilibrium strategy 1 , and $\left(p_{r 1}^{f *}, w_{2}^{*}, p_{e 2}^{*}\right)$ is referred to as equilibrium strategy 2 . The two scenarios used for the supply chain are simple; in scenario 1 , the retailer does not have fairness concerns, and in scenario 2 , the retailer does.

The decision analyses of the retailer and manufacturer are shown as follows. (i) In scenario 2, when the crossprice sensitivity coefficient is normal, $\theta=0.3$, and the level of the retailer's fairness concern is less. The manufacturer will set a high wholesale price and direct channel price to reduce the profits of an ambitious retailer in a traditional retail channel, which results in a disadvantageous inequality. As $\alpha$ increases, meaning that the retailer's sense of fairness grows stronger, the manufacturer sets a lower $w_{1}^{*}$ and $p_{e 1}^{*}$, and the retailer will set a higher retail price $p_{r 1}^{f *}$. When the parameters exceed the threshold $\bar{\alpha}(0.57)$, the manufacturer will adopt equilibrium strategy 2 , which consists of a lower $w$ 


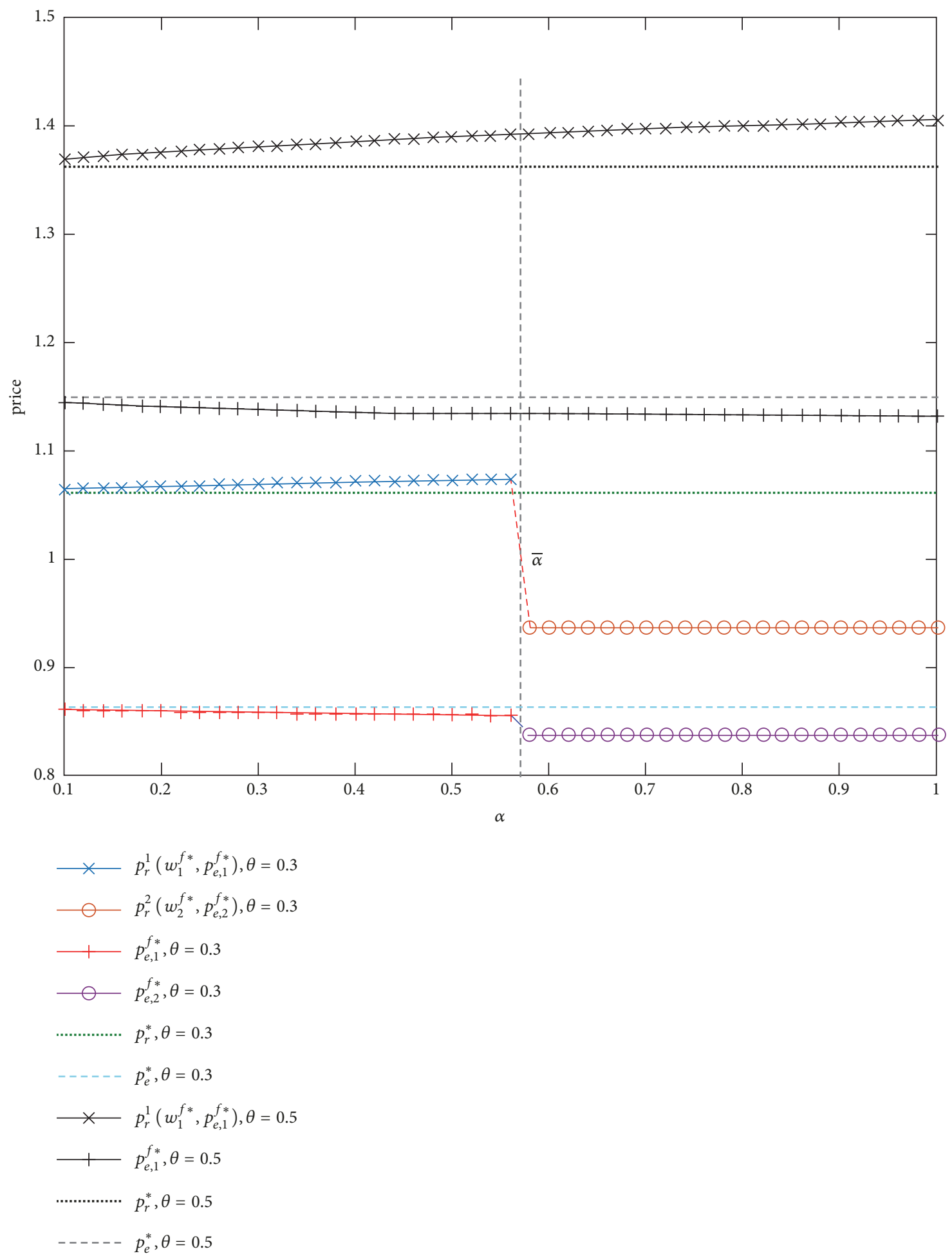

FIgURE 3: Impact of $\theta$ and $\alpha$ on online and offline prices.

and $p_{e}$, to achieve channel fairness. (ii) In scenario 2, when the cross-price sensitivity coefficient is high, $\theta=0.5$, the price strategies of the retailer and manufacturer are all higher than before $(\theta=0.5)$. Another interesting phenomenon is observed. As the cross-sensitivity coefficient increases, the manufacturer becomes more likely to always adopt one strategy without considering the disadvantageous inequality, which leads the retailer to care more about fairness. This phenomenon reflects the diversity of strategies used by members, which conflicts with the conclusions of Qinghua Li [29] and proves Proposition 5. (iii) The wholesale price and online direct price in scenario 2 are always lower than those 


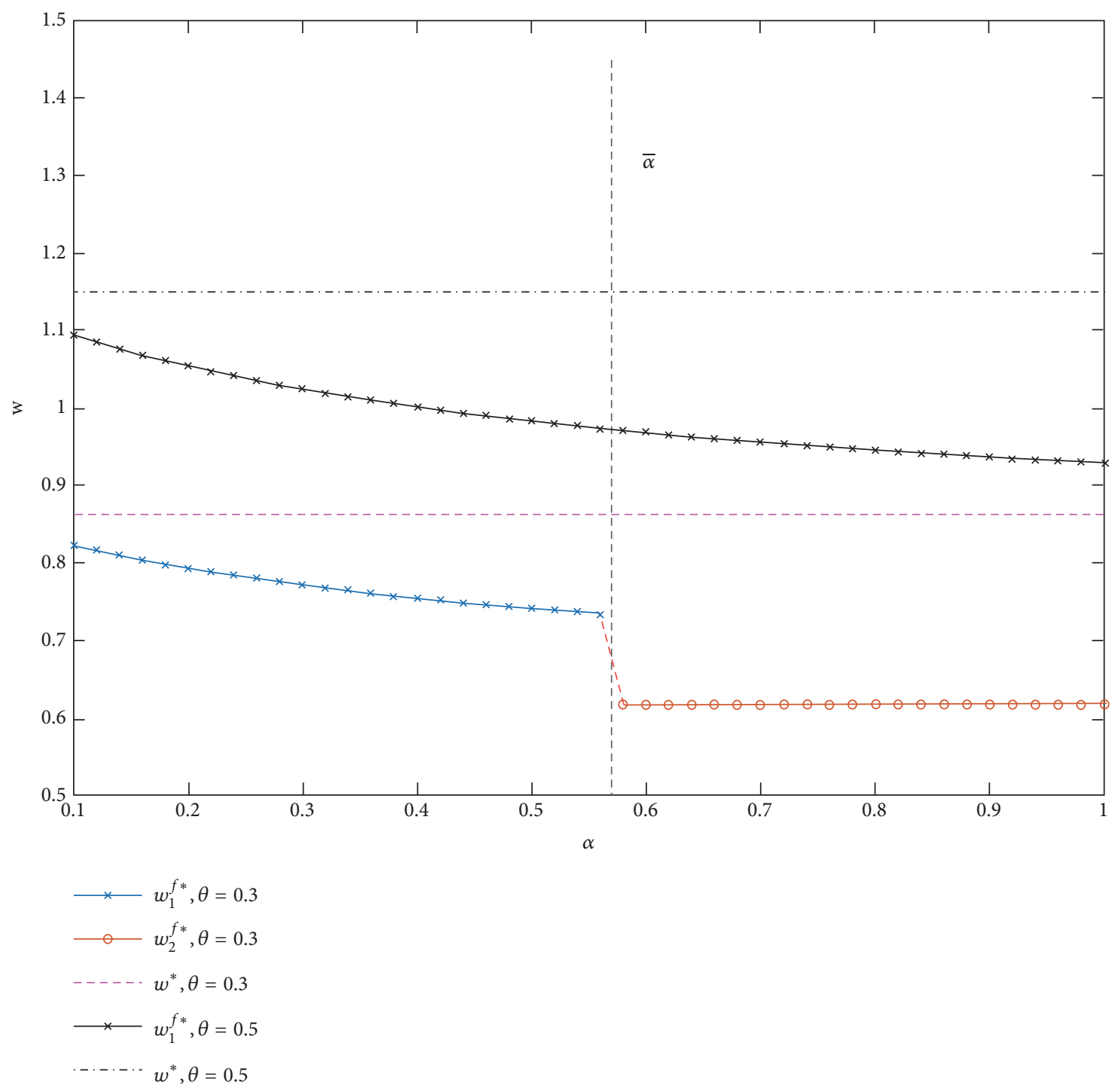

Figure 4: Impact of $\theta$ and $\alpha$ on $w$.

for scenario 1 , and the gaps slowly increase as $\alpha$ increases. Compared to the manufacturer, the offline retail price set by the retailer in scenario 2 is lower than that in scenario 1 only when the fairness channel exists. (iv) Retailers with a stronger fairness concern are more likely to enter a neutral state or obtain a fairness result.

Observation 7 (changes in the profits and utility of the members).

(1) Effects of $\theta$ and $\alpha$ on the Manufacturer's Profit. We can deduce some information by observing Figure 5. (i) In Figure $5, \theta=0.3$, and the manufacturer adopts equilibrium strategy 1 , as the profit of this strategy is higher than that of equilibrium strategy 1 . As $\alpha$ increases, the gap between the two strategies decreases. Therefore, the manufacturer will change its strategy if the level of the fairness concern of the retailer exceeds a threshold $\bar{\alpha}$. A comparison of the profit for the manufacturer's two strategies is proof of the previous analysis in Observation 6. While the cross-price sensitivity coefficient is high, when $\theta=0.5$, the manufacturer will always adopt equilibrium strategy 1 even though the corresponding profit decreases as $\alpha$ increases. This phenomenon occurs because the manufacturer would rather have a disadvantageous inequality existing than preserve a fairness channel that could hurt his interest. (ii) Due to retailer's behavior related to his fairness concern, the manufacturer's profit is always less than in scenario 1. (iii) Cross-price sensitivity has a positive effect on the manufacturer.

(2) Effects of $\theta$ and $\alpha$ on the Retailer's Profit and Utility. Figure 6 shows the utility and profit of the retailer. Similarly, the analysis has some implications. (i) Compared to scenario 1 , the profit and utility of the retailer increase because of his fairness concern, which differs from that of the manufacturer. (ii) The retailer's utility $(\theta=0.3)$ is more than that for $(\theta=$ 0.5 ) as $\alpha$ increases. If $\alpha>\bar{\alpha}$, the fairness channel exists, and both the utility and profit increase considerably. It can be seen 


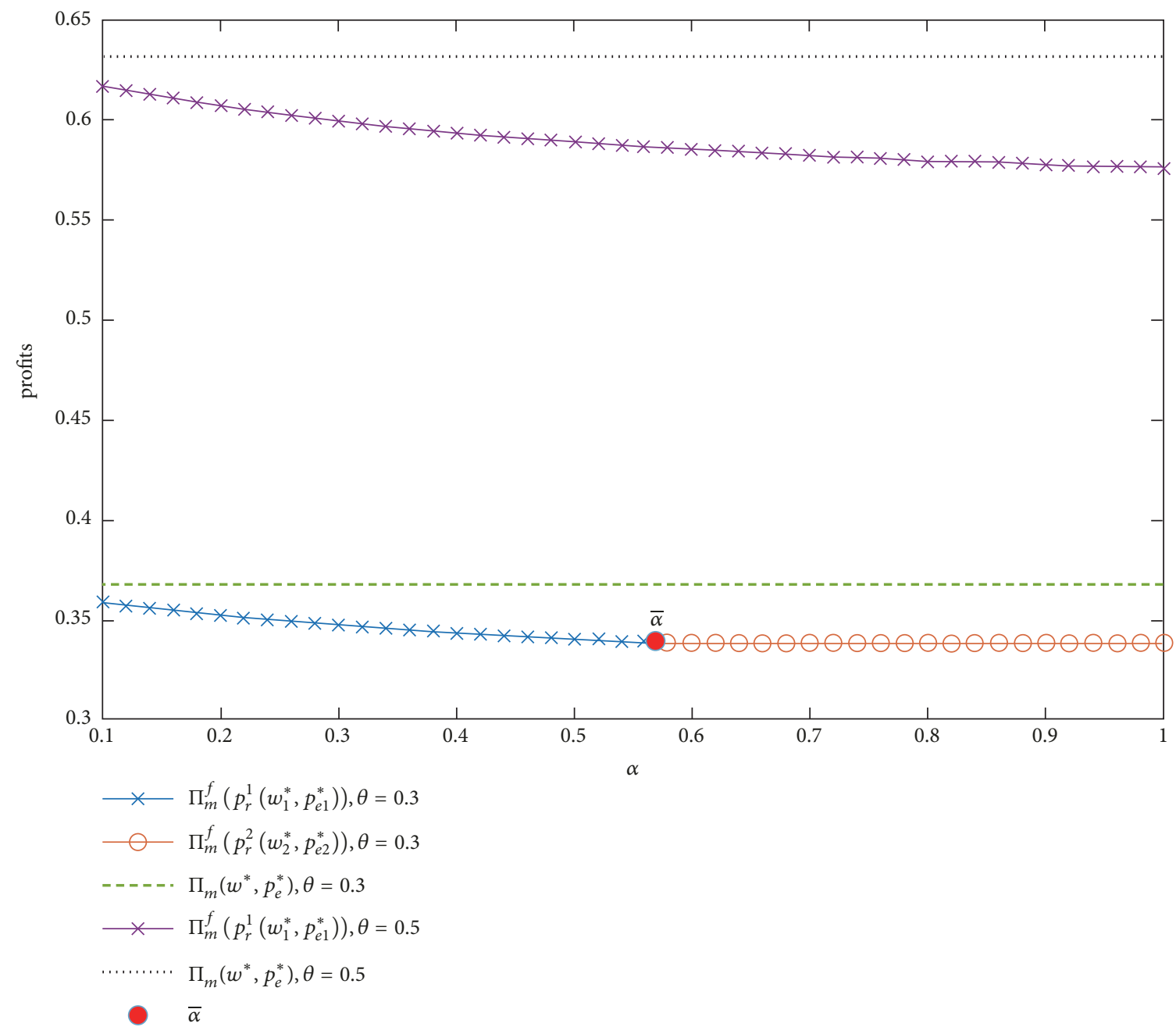

Figure 5: Impact of $\theta$ and $\alpha$ on $\pi_{m}^{f}$ for the two scenarios.

that fairness concerns have a greater effect on the retailers than cross-price sensitivity.

Observation 8 (changes in channel efficiency). The fairness concern of the retailer will affect the decisions and profits of the members. To further illustrate the impact of the retailer's fairness concerns on double marginalization, we use $\left(\pi_{r}^{f *}+\right.$ $\left.\pi_{m}^{f *}\right) / \pi_{c}^{c *}$ to present the channel efficiencies, as done in [29], where $\pi_{c}^{c *}$ represents the total profit of the centralized supply chain. Figure 7 illustrates how the channel efficiencies change as $\alpha$ increases and $\theta$ changes.

Figure 7 provides valuable information. (i) An increase in $\alpha$ widens the gap between the two scenarios when the retailers' fairness concerns do not reach a certain level $\bar{\alpha}$ $(\alpha<\bar{\alpha})$. The intuitive explanations for this result are as follows. As $\alpha$ increases, the manufacturer reduces both the wholesale prices and the network direct prices, while the retailers raise retail prices to boost their profits, which leads to double marginalization. (ii) We discuss the situation in which the level of the retailers' fairness concerns exceeds the threshold $(\alpha>\bar{\alpha})$. In this case, cross-price sensitivity is normal. The manufacturer adopts a lower pricing strategy because he is focused on the retailer's fairness concerns. This adjustment results in a fairness channel. Then, the retailer obtains a greater profit even after setting a lower price. The performance of the supply chain is obviously enhanced and tends towards Pareto optimality. Simultaneously, crossprice sensitivity is high. Channel efficiency decreases as $\alpha$ increases. This change can be explained by the fact that the manufacturer's strategy considers his own interests, and he did not provide a fair distribution for the retailer. (iii) The supply chain cannot be coordinated by a constant wholesale price in scenarios 1 and 2.

\section{Concluding Remarks}

In this paper, we considered a dual-channel supply chain that includes one manufacturer and one retailer. A supplydemand relationship and a competitive relationship will coexist between the manufacturer and retailer after an online direct marketing channel opens. Based on this complex relationship, we investigated the considered model with two 


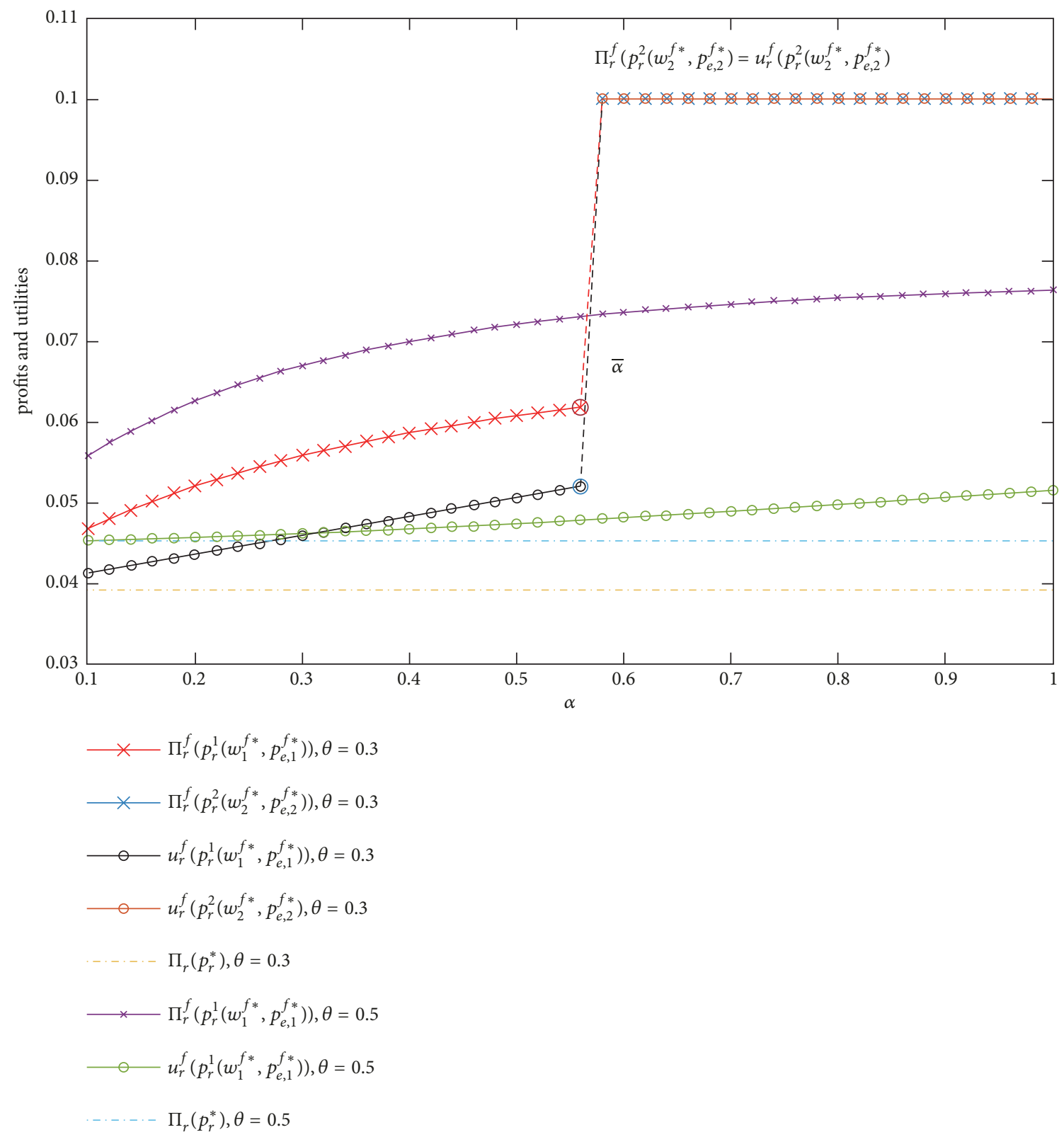

FIgURE 6: Impact of $\theta$ and $\alpha$ on $\pi_{r}^{f}$ and $u_{r}^{f}$ for the two scenarios.

scenarios to represent whether the retailer has fairness concerns. Simultaneously, the cross-price sensitivity coefficient, which affects the price competition between dual channels, is emphasized in the analysis of pricing decisions. By theoretical derivation, we get the following conclusions and management enlightenments as follows.

When the manufacturer faces a rational retailer, the optimal pricing strategy of the decentralized supply chain members are increasing functions of the cross-price coefficient $\theta$. Therefore, the enterprise managers can set a relatively high retail price, and its negative effect on channel demand will be weakened when all channel consumers pay more attention to price comparison between channels. The result is more conducive to improving the profits of supply chain.
The channel efficiency of the decentralized supply chain is an increasing function of the cross-price coefficient $\theta$, which indicates that the double marginalization will be weakened when $\theta$ increases.

Retailers' fair concern behavior has an impact on price strategy. We integrate fair concern into the study of price strategy. Different from previous studies, this paper deduce a complete set of pricing decisions when manufacturers balance channel fairness and self-interest. $\theta$ and $\alpha$ codetermine the manufacturer's final decision which reflect that rational manufacturers should take into account both the crossprice impact between channels and retailers' fair behavior when formulating pricing strategies. The decision set reflects that when the cross-price influence coefficient is fixed, the 


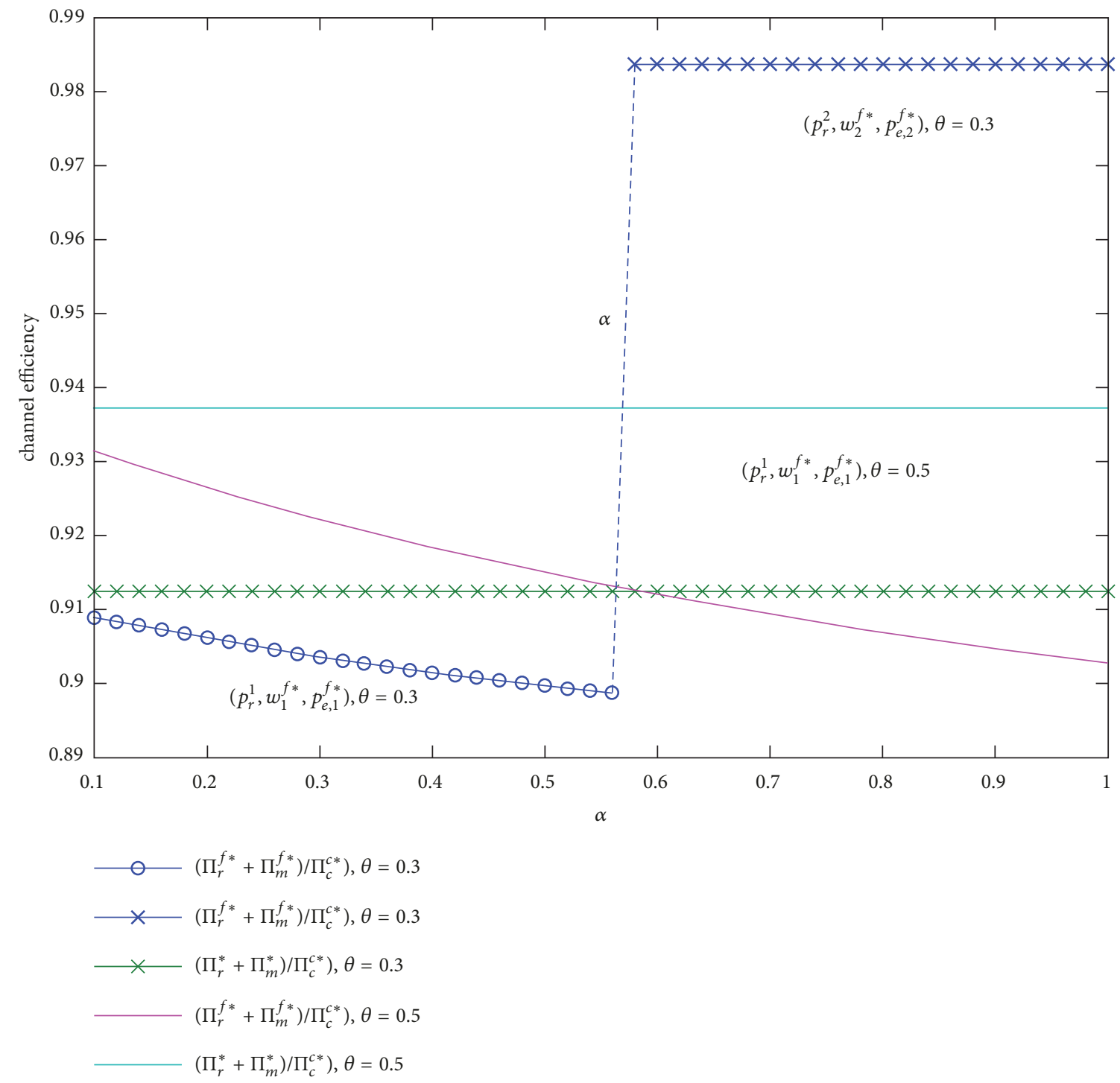

FIGURE 7: Impact of $\theta$ and $\alpha$ on channel efficiencies for the two scenarios.

retailers with stronger fair concern are more likely to impel the manufacturer to make a relatively fair price strategy.

Furthermore, by numerical experiments, the thesis and propositions are verified. Some findings and the corresponding management implications are given as follows.

When the cross-price influence between channels is lower, retailers that are more concern about fairness impel manufacturers set a lower wholesale price and online direct price which is conducive to channel coordination. This phenomenon is consistent with previous inference. When the cross-price influence between channels is higher, manufacturers establish higher price strategies which are more beneficial for their own interests. Considering the retailer's fairness concerns, the cross-price effect is not always conducive to supply chain coordination, which is different from the situation facing rational retailers. Therefore, when confronting a retailer with strong fairness concerns, it is more suitable for the manufacturer to cooperate when the cross-price impact between channels is relatively low. In contrast, among those retailers less concerned about fairness, rational retailers would be better partners.

In order to further explore the article's conclusions on the application value of supply chain management. A natural extension of our research would be to test our model predictions. For example, our analysis predicts that the manufacturer will obtain less profit when he provides a fair distribution for the retailer in the offline retail channel. In the home furnishings industry of China, the offline retailers feel that they have been unfairly treated based on the loss of profits due to direct channels. Some brands such as KUKA propose giving $10-15 \%$ of their profits to dealers [44]. To enhance offline marketing, Vivo surrenders a greater portion of the profits to offline mobile phones retailers, while some brands do not give enough profits, which results in low sales enthusiasm on the part of retailers [45, 46]. 
The demand functions are constructed for the dualchannel supply chain with homogeneous channel. The implication of this paper has limitations to some extent. Not all product consumers are primarily concerned with price when choosing shopping channel. Furthermore, some manufacturers adopt a heterogeneous product strategy to effectively alleviate the channel conflict. Therefore, considering the heterogeneity of channels and conducting a systematic statistical analysis of our model is a significant topic for future research.

\section{Appendix}

\section{A. Proof of Lemma 2}

In region 1, the manufacturer's problem is as follows:

$$
\begin{array}{ll}
\max & \pi_{m 1}^{f}=d_{e}\left(p_{e}-c\right)+d_{r}(w-c) \\
\text { s.t } \quad & p_{r}=\frac{w(2 \alpha+1)}{2(\alpha+1)}+\frac{\theta p_{e}}{2}+\frac{a+\alpha(a-c)}{2(\alpha+1)}, \\
& p_{e}<K_{1} w-D_{1}, \\
& p_{e} \geq K_{3} w-D_{3}, \\
& p_{e}>K_{4} w-D_{4}, \\
p_{e} & <K_{5} w-D_{5} .
\end{array}
$$

Therefore, the Hessian matrix of the manufacturer's profit function can be calculated.

$$
H_{\pi_{m .1}}\left[\begin{array}{c}
p_{e} \\
w
\end{array}\right]=\left[\begin{array}{cc}
\theta^{2}-2 & \frac{\theta(3 \alpha+2)}{2(\alpha+1)} \\
\frac{\theta(3 \alpha+2)}{2(\alpha+1)} & \frac{-2 \alpha-1}{\alpha+1}
\end{array}\right]
$$

There is a threshold for the cross-price sensitivity coefficient, $\bar{\theta}_{1}=2 \sqrt{2\left(2 \alpha^{2}+3 \alpha+1\right) /\left(17 \alpha^{2}+24 \alpha+8\right)}$. When $\theta \in\left(0, \bar{\theta}_{1}\right)$, the Hessian matrix is negative definite. The manufacturer's profit function is a concave function of $p_{e}$ and $w$, and the decision problem is a convex optimization problem. Thus, a unique extreme point exists. If the extreme point is in the feasible region, then the extreme point is the partial equilibrium solution for the manufacturer. In contrast, the partial equilibrium solution is on the boundary of R1. If $\bar{\theta}_{1} \leq \theta<1$, the Hessian matrix is neither negative definite nor positive, which can be easily proved. In this case, there is no extreme point in the feasible region, which suggests that the optimal solution in $\mathrm{R} 1$ is on the boundary.

The process of deduction is as follows:

(1) For inferring the complete partial equilibrium solutions in R1, some basic work should be solved, including the extreme point, the optimal value of the boundary and the corresponding parameter range. This part is given in Appendix A.1.

(2) By comparing the results of Appendix A.1, we could deduce the partial equilibrium solution and the corresponding parameter range when the Hessian matrix is negative definite $\left(0<\theta<\bar{\theta}_{1}\right)$. This part is given in Appendix A.2.

(3) When $\bar{\theta}_{1} \leq \theta<1$, we should determine the optimal value of each boundary of R1 and the corresponding parameter range. By comparing the results of Appendix A.1, we can obtain the corresponding partial equilibrium solutions. This part is given in Appendix A.3.

A.1. Basic Work. (1)The optimal solution on boundary L1 and the corresponding parameter range are as follows.

The manufacturer's problem is as follows:

$$
\begin{aligned}
\max _{p_{e, w}} & \pi_{m 1}^{f}=d_{e}\left(p_{e}-c\right)+d_{r}(w-c) \\
\text { s.t } \quad p_{r}^{f} & =\frac{w(2 \alpha+1)}{2(\alpha+1)}+\frac{\theta p_{e}}{2}+\frac{a+\alpha(a-c)}{2(\alpha+1)} \\
p_{e} & =K_{1} w-D_{1}, \\
w_{C} & \leq w \leq w_{A}
\end{aligned}
$$

The optimal profit of the manufacturer on $\mathrm{L} 1$ is

$$
\begin{aligned}
\bar{w}_{1,1}^{f *} & =\frac{Y 1 a+Y 2 c}{X}, \\
\bar{p}_{e 1,1}^{f *} & =\frac{Y 3 a+Y 4 c}{X},
\end{aligned}
$$

where

$$
\begin{aligned}
Y 1= & -2 \theta^{2} \alpha^{2}-4 \theta^{2} \alpha+2 \theta \alpha^{2}-2 \theta^{2}+5 \theta \alpha+4 \alpha^{2} \\
& +3 \theta+10 \alpha+6 \\
Y 2= & Y 2-(\alpha+1)^{2} \theta^{3}-\left(2 \alpha^{2}+9 \alpha+7\right) \theta^{2}+4 \alpha+6, \\
Y 3= & 4 \theta \alpha^{2}+12 \theta \alpha+4 \alpha^{2}+8 \theta+12 \alpha+9, \\
Y 4= & -4 \theta^{2} \alpha^{2}-10 \theta^{2} \alpha-6 \theta^{2}+4 \alpha^{2}+\theta+12 \alpha+9 .
\end{aligned}
$$

When $0<\theta<1$, we have $w_{C}<\bar{w}_{1,1}^{f *}<w_{A}$. Then, the corresponding profit is

$$
\pi_{m 1}^{f}\left(\bar{w}_{1,1}^{f *}, \bar{p}_{e 1,1}^{f *}\right)=\frac{-\left(4(\alpha+1)^{2} \theta^{2}+8\left(\alpha^{2}+3 \alpha+2\right) \theta+4 \alpha^{2}+16 \alpha+13\right)(\theta c+a-c)^{2}}{4\left(4 \alpha^{2}+11 \alpha+7\right) \theta^{2}-4(2 \alpha+3)^{2}}
$$


(2)The optimal solution on boundary L3 and the corresponding parameter range are as follows:

$$
\begin{aligned}
\max _{p_{e, w}} & \pi_{m 1}^{f}=d_{e}\left(p_{e}-c\right)+d_{r}(w-c) \\
\text { s.t } \quad & p_{r}^{f}=\frac{w(2 \alpha+1)}{2(\alpha+1)}+\frac{\theta p_{e}}{2}+\frac{a+\alpha(a-c)}{2(\alpha+1)} \\
p_{e} & =K_{3} w-D_{3},
\end{aligned}
$$

$$
w_{C} \leq w \leq w_{J}
$$

$\left(\bar{w}_{1,3}, \bar{p}_{e, 1,3}\right)$ denotes the decision of the manufacturer on this boundary, and the remainder of the boundaries follow this method. By solving the problem, we can obtain the following:

$$
\text { If } 0<\theta \leq \bar{\theta}_{9}
$$

$$
\begin{aligned}
& \bar{w}_{1,3}=\bar{w}_{1,3}^{f *}=\frac{c(\alpha+1) \theta^{2}+((4 c-a) \alpha-a+2 c) \theta-(3 a+5 c) \alpha-3(a+c)}{2((\alpha+1) \theta+4 \alpha+3)(\theta-1)}, \\
& \bar{p}_{e 1,3}=\bar{p}_{e 1,3}^{f *}=\bar{w}_{1,3}^{f *} .
\end{aligned}
$$

If $\bar{\theta}_{9}<\theta<1$

$$
\begin{aligned}
\bar{w}_{1,3} & =w_{J}, \\
\bar{p}_{e 1,3} & =p_{e, J}, \\
\bar{\theta}_{9} & =\frac{-5 \alpha-2+\sqrt{33 \alpha^{2}+40 \alpha+16}}{2(\alpha+1)} .
\end{aligned}
$$

(3)The optimal solution on boundary L4 and the corresponding parameter range are as follows:

$$
\begin{aligned}
\max _{p_{e, w}} & \pi_{m 1}^{f}=d_{e}\left(p_{e}-c\right)+d_{r}(w-c) \\
\text { s.t } \quad p_{r}^{f} & =\frac{w(2 \alpha+1)}{2(\alpha+1)}+\frac{\theta p_{e}}{2}+\frac{a+\alpha(a-c)}{2(\alpha+1)} \\
& p_{e}=K_{4} w-D_{4}, \\
w_{J} & \leq w<w_{M}
\end{aligned}
$$

By solving the problem, we can obtain the following: If $0<\theta<1 /(\alpha+1)$,

$$
\begin{aligned}
\bar{w}_{1,4} & =w_{J}, \\
\bar{p}_{e 1,4} & =p_{e, J} .
\end{aligned}
$$

$$
\begin{aligned}
& \text { If } 1 /(\alpha+1) \leq \theta<1 \\
& \bar{w}_{1,4}=\bar{w}_{1,4}^{f *} \\
& =\frac{\left((\alpha+1) \theta^{2}+(\alpha-1) \theta-2 \alpha\right) c+(\alpha+1)(\theta-2) a}{(4 \alpha+2)(\theta-1)}, \\
& \bar{p}_{e 1,4}=\bar{p}_{e 1,4}^{f *}=\frac{a+c-\theta c}{2(1-\theta)} .
\end{aligned}
$$

(4)The optimal solution on boundary L5 and the corresponding parameter range are as follows:

$$
\begin{aligned}
\max _{p_{e, w}} & \pi_{m 1}^{f}=d_{e}\left(p_{e}-c\right)+d_{r}(w-c) \\
\text { s.t } \quad p_{r}^{f} & =\frac{w(2 \alpha+1)}{2(\alpha+1)}+\frac{\theta p_{e}}{2}+\frac{a+\alpha(a-c)}{2(\alpha+1)} \\
p_{e} & =K_{5} w-D_{5}, \\
w_{A} & \leq w<w_{M}
\end{aligned}
$$

By solving the problem, we can obtain the following: If $0<\theta^{2} \leq 1-1 / 2 \alpha$,

$$
\begin{aligned}
& \bar{w}_{1,5}=w_{A}, \\
& \bar{p}_{e 1,5}=p_{e, A} .
\end{aligned}
$$

If $1-1 / 2 \alpha<\theta^{2} \leq 1$,

$$
\begin{aligned}
& \bar{w}_{1,5}=\bar{w}_{1,5}^{f *}=\frac{(3 \alpha+1)(\theta-1) c-(\alpha+1) a}{(4 \alpha+2)(\theta-1)}, \\
& \bar{p}_{e 1,7}=\bar{p}_{e 1,5}^{f *}=\frac{\left(\theta-\theta^{2}\right) c+\left(4-2 \theta^{2}-\theta\right)}{2(\theta-1)\left(\theta^{2}-2\right)} .
\end{aligned}
$$

(5)The extreme point of the manufacturer's profit function is as follows. 
By solving the equations above for $w$ and $p_{e}$, we can obtain the extreme point as follows:

$$
\begin{gathered}
w_{1}^{f *}=\frac{-\left(\left(\theta^{2}+6 \theta+4\right) \alpha^{2}+\left(\theta^{2}+10 \theta+8\right) \alpha+4 \theta+4\right) a}{X_{1}} \\
+\frac{\left(\left(-\theta^{3}+12 \theta^{2}+2 \theta-12\right) \alpha^{2}+\left(-\theta^{3}+15 \theta^{2}+2 \theta-16\right) \alpha+4 \theta^{2}-4\right) c}{X_{1}}, \\
p_{e, 1}^{f *}=\frac{-\left((7 \theta+8) \alpha^{2}+(11 \theta+12) \alpha+4 \theta+4\right) a}{X_{1}}+\frac{\left(\left(10 \theta^{2}-\theta-8\right) \alpha^{2}+\left(13 \theta^{2}-\theta-12\right) \alpha+4 \theta^{2}-4\right) c}{X_{1}},
\end{gathered}
$$

where $X_{1}=17 \theta^{2} \alpha^{2}+24 \theta^{2} \alpha+8 \theta^{2}-16 \alpha^{2}-24 \alpha-8$.

\section{A.2. Inferring the Partial Equilibrium Solution When $0<\boldsymbol{\theta}<\overline{\boldsymbol{\theta}}_{1}$.} We substitute $w_{1}^{f *}$ and $p_{e, 1}^{f *}$ into all the boundaries. "+" denotes the extreme point that satisfies the corresponding constraint; similarly, "-" indicates that the constraint is not satisfied. The results of all the constraints are summarized in Table 5.

Analysis 1 (if $\left\{\left\{0<\alpha \leq \alpha_{1}\right\} \cap\left\{0<\theta \leq \bar{\theta}_{3}\right\}\right\} \cup\left\{\left\{\alpha_{1}<\alpha<1\right\}\right.$ $\left.\cap\left\{\bar{\theta}_{2}<\theta \leq \bar{\theta}_{3}\right\}\right\}$ ). The extreme point satisfies all the constraints. Thus, the corresponding partial equilibrium solution in this situation is

$$
\left(w_{1}^{f}, p_{e, 1}^{f}\right)=\left(w_{1}^{f *}, p_{e, 1}^{f *}\right) .
$$

Analysis 2 (if $\left\{\alpha_{1}<\alpha<1\right\} \cap\left\{0<\theta \leq \bar{\theta}_{2}\right\}$ ). Based on Table 5, only constraint (L3) is not satisfied, which implies that the partial equilibrium solution is on the boundary of L3. Combined with the results for L3 of Appendix A.1, we can prove that $\bar{\theta}_{2}<\bar{\theta}_{9}$. Therefore, we can infer the corresponding partial equilibrium solution in this situation:

$$
\left(w_{1}^{f}, p_{e, 1}^{f}\right)=\left(\bar{w}_{1,3}^{f *}, \bar{p}_{e, 1,3}^{f *}\right) .
$$

Analysis 3 (if $\{0<\alpha<1\} \cap\left\{\bar{\theta}_{3}<\theta<\bar{\theta}_{1}\right\}$ ). Based on Table 5, only constraint (L3) is not satisfied, which implies that the partial equilibrium solution is on the boundary of L3. Combined with the result of $\mathrm{L} 3$ of Appendix A.1, we can prove that $1 /(\alpha+1)<\bar{\theta}_{3}$. Therefore, we can infer the corresponding partial equilibrium solution in this situation:

$$
\left(w_{1}^{f}, p_{e, 1}^{f}\right)=\left(\bar{w}_{1,4}^{f *}, \bar{p}_{e 1,4}^{f *}\right) .
$$

\section{A.3. Inferring the Partial Equilibrium Solution When $\boldsymbol{\theta} \in$ $\left[\overline{\boldsymbol{\theta}}_{1}, 1\right)$}

Analysis 4. In this case, there are no extreme points in the feasible region, which suggests that the optimal solution in $\mathrm{R} 1$ is on the boundary. We need to infer and compare the solutions of L1, L3, L4, and L5.

(1) For all $\alpha \in(0,1)$, it is easy prove that $\bar{\theta}_{1}>(-5 \alpha-2+$ $\left.\sqrt{33 \alpha^{2}+40 \alpha+16}\right) / 2(\alpha+1), \bar{\theta}_{1}>1 /(\alpha+1)$, and $1-1 / 2 \alpha<$ $\left(\bar{\theta}_{1}\right)^{2}$. Then, we can infer the solution on each boundary, which is shown in (2)-(5).

(2)

$$
\pi_{m 1}\left(\bar{w}_{1,1}, \bar{p}_{e 1,1}\right)=\pi_{m 1}\left(\bar{w}_{1,1}^{f *}, \bar{p}_{e 1,1}^{f *}\right)=\frac{-\left(4(\alpha+1)^{2} \theta^{2}+8\left(\alpha^{2}+3 \alpha+2\right) \theta+4 \alpha^{2}+16 \alpha+13\right)(\theta c+a-c)^{2}}{4\left(4 \alpha^{2}+11 \alpha+7\right) \theta^{2}-4(2 \alpha+3)^{2}} .
$$

(3)

$$
\pi_{m 1}\left(\bar{w}_{1,3}, \bar{p}_{e 1,3}\right)=\pi_{m 1}\left(\bar{w}_{J}, \bar{p}_{e, J}\right) .
$$

(4)

$$
\begin{aligned}
\pi_{m 1}\left(\bar{w}_{1,4}, \bar{p}_{e 1,4}\right) & =\pi_{m 1}\left(\bar{w}_{1,4}^{f *}, \bar{p}_{e 1,4}^{f *}\right) \\
& =\frac{(\theta+1)(\theta c+a-c)^{2}}{4(1-\theta)} .
\end{aligned}
$$

(5)

$$
\begin{aligned}
\pi_{m 1}\left(\bar{w}_{1,5}, \bar{p}_{e 1,5}\right) & =\pi_{m 1}\left(\bar{w}_{1,5}^{f *}, \bar{p}_{e 1,5}^{f *}\right) \\
& =\frac{(\alpha+1)(\theta+1)(\theta c+a-c)^{2}}{4(1-\theta)\left(2-\theta^{2}\right)(2 \alpha+1)} .
\end{aligned}
$$

Combined with (2)-(5), we can calculate it further. 
TABLE 5

\begin{tabular}{lccccc}
\hline$\alpha$ & \multicolumn{3}{c}{$\left(0, \alpha_{1}\right]$} & \multicolumn{3}{c}{$\left(\alpha_{1}, 1\right)$} \\
\hline$\theta$ & $\left(0, \bar{\theta}_{3}\right]$ & $\left(\bar{\theta}_{3}, \bar{\theta}_{1}\right)$ & $\left(0, \bar{\theta}_{2}\right]$ & $\left(\bar{\theta}_{2}, \bar{\theta}_{3}\right]$ & $\left(\bar{\theta}_{3}, \bar{\theta}_{1}\right)$ \\
\hline $\mathrm{L} 1$ & + & + & + & + & + \\
\hline $\mathrm{L} 3$ & + & + & - & + & + \\
\hline $\mathrm{L} 4$ & + & - & + & + & - \\
\hline $\mathrm{L} 5$ & + & + & + & + & + \\
\hline $\bar{\theta}_{2}=\left(-2 \alpha^{2}-7 \alpha-4+\sqrt{100 \alpha^{4}+204 \alpha^{3}+113 \alpha^{2}+8 \alpha}\right) / 4\left(3 \alpha^{2}+4 \alpha+1\right)$ \\
$\bar{\theta}_{3}=2(\alpha+1) /(3 \alpha+2), \bar{\theta}_{1}=2 \sqrt{2\left(2 \alpha^{2}+3 \alpha+1\right) /\left(17 \alpha^{2}+24 \alpha+8\right)}$, and \\
$\alpha_{1}=1 / 2$.
\end{tabular}

(6)

$$
\begin{aligned}
\pi_{m 1}\left(\bar{w}_{1,3}, \bar{p}_{e 1,3}\right) & =\pi_{m 1}\left(\bar{w}_{J}, \bar{p}_{e, J}\right) \\
& \leq \pi_{m}\left(\bar{w}_{1,4}^{f *}, \bar{p}_{e 1,4}^{f *}\right) .
\end{aligned}
$$

(7)

$$
\begin{aligned}
\pi_{m 1}\left(\bar{w}_{1,4}^{f *}, \bar{p}_{e 1,4}^{f *}\right)-\pi_{m 1}\left(\bar{w}_{1,5}^{f *}, \bar{p}_{e 1,5}^{f *}\right) \\
=\frac{\left(2 \theta^{2} \alpha+\theta^{2}-3 \alpha-1\right)(\theta+1)(\theta c+a-c)^{2}}{4(1-\theta)\left(2-\theta^{2}\right)(2 \alpha+1)}
\end{aligned}
$$

$$
>0 \text {. }
$$

(8)

$$
\begin{aligned}
& \pi_{m 1}\left(\bar{w}_{1,4}^{f *}, \bar{p}_{e 1,4}^{f *}\right)-\pi_{m 1}\left(\bar{w}_{1,1}^{f *}, \bar{p}_{e 1,1}^{f *}\right) \\
& =\frac{\left((\alpha+1)\left(3 \theta^{3}-5 \theta^{2}-4 \theta+4\right)-2 \theta\right)(\theta c+a-c)^{2}}{4(1-\theta)\left(\left(4 \alpha^{2}+11 \alpha+7\right) \theta^{2}-(2 \alpha+3)^{2}\right)} \\
& >0 .
\end{aligned}
$$

Combined with (6)-(8), we can confirm that the partial equilibrium solution is

$$
\left(w_{1}^{f}, p_{e, 1}^{f}\right)=\left(\bar{w}_{1,4}^{f *}, \bar{p}_{e, 1,4}^{f *}\right) .
$$

By summarizing Analyses 1-4, we can obtain the partial equilibrium solution set in region $\mathrm{R} 1$, which is shown in Table 2.

\section{B. Proof of Lemma 3}

The problem of the manufacturer is

$$
\begin{aligned}
\max & \pi_{m 2}^{f}=d_{e}\left(p_{e}-c\right)+d_{r}(w-c) \\
\text { s.t } & p_{r}^{f}=2 w-c \\
& p_{e}>K_{1} w-D_{1}, \\
& p_{e}<K_{3} w-D_{3}, \\
& p_{e}>K_{4} w-D_{4}, \\
& w>c
\end{aligned}
$$

There is a threshold for the cross-price sensitivity coefficient, $\bar{\theta}_{4}=2 \sqrt{2} / 3$. When $\theta \in\left(0, \bar{\theta}_{4}\right)$, the Hessian matrix is negatively definite. If $\bar{\theta}_{4} \leq \theta<1$, then the Hessian matrix is neither negative definite nor positive definite. Similarly, we use a method such as Lemma 2 to deduce the conclusion.

B.1. Basic Work. (1)The result is the same as Appendix A.1.

(2)The optimal solution on boundary L2 and the corresponding parameter range are as follows:

$$
\begin{aligned}
\bar{w}_{2,2}^{f *}= & \frac{\left(2 \theta^{2}-3 \theta-6\right) a}{14 \theta^{2}-18}+\frac{\left(2 \theta^{3}+9 \theta^{2}-3 \theta-12\right) c}{14 \theta^{2}-18}, \\
\bar{p}_{e 2,2}^{f *}= & \frac{-(8 \theta+9) a}{14 \theta^{2}-18}+\frac{\left(6 \theta^{2}-\theta-9\right) c}{14 \theta^{2}-18} .
\end{aligned}
$$

For all $\theta \in(0,1), \alpha \in(0,1), w_{\mathrm{Q}}<\bar{w}_{2,2}^{f *}<w_{E} \alpha \in(0,1)$.

(3) The optimal solution on boundary L3 and the corresponding parameter range are as follows:

$$
\begin{aligned}
\left(\bar{w}_{2,3}, \bar{p}_{e 2,3}\right) & = \begin{cases}\left(\bar{w}_{2,3}^{f *}, \bar{p}_{e 2,3}^{f *}\right) & \text { if } 0<\theta \leq \frac{\alpha}{2(\alpha+1)} \\
\left(w_{C}, p_{e, C}\right) & \text { if } \frac{\alpha}{2(\alpha+1)}<\theta<1\end{cases} \\
\bar{w}_{2,3}^{*} & =\frac{a}{3-3 \theta}+\frac{2}{3} c, \\
\bar{p}_{e 2,3}^{*} & =\frac{a}{3-3 \theta}+\frac{2}{3} c .
\end{aligned}
$$

(4)The optimal solution on boundary L6 and the corresponding parameter range are as follows:

$$
\begin{aligned}
& \left(\bar{w}_{2,6}, \bar{p}_{e 2,6}\right) \\
& =\left\{\begin{array}{l}
\left(\bar{w}_{2,6}^{*}, \bar{p}_{e 2,6}^{f *}\right) \quad \text { if } 0<\theta \leq \frac{\sqrt{2(\alpha+1)(2 \alpha+1)}}{2(\alpha+1)} \\
\left(w_{A}, p_{e, A}\right) \quad \text { if } \frac{\sqrt{2(\alpha+1)(2 \alpha+1)}}{2(\alpha+1)}<\theta<1
\end{array}\right. \\
& \bar{w}_{2,6}^{f *}=\frac{a}{4-4 \theta}+\frac{3}{4} c, \\
& \bar{p}_{e 2,6}^{f *}=\frac{(2-\theta) a}{2-2 \theta}+\frac{\theta}{2} c .
\end{aligned}
$$

(5)The extreme point of the manufacturer's profit function is as follows:

$$
\begin{aligned}
& w_{2}^{f *}=\frac{(3 \theta+2) a}{8-9 \theta^{2}}-\frac{\left(6 \theta^{2}+\theta-6\right) c}{8-9 \theta^{2}} ; \\
& p_{e 2}^{f *}=\frac{(3 \theta+4) a}{8-9 \theta^{2}}-\frac{\left(6 \theta^{2}-\theta-4\right) c}{8-9 \theta^{2}} .
\end{aligned}
$$

B.2. Inferring the Partial Equilibrium Solution When $0<\boldsymbol{\theta}<\overline{\boldsymbol{\theta}}_{4}$. We substitute $\left(w_{2}^{f *}, p_{e, 2}^{f *}\right)$ into each boundary. “+” indicates that the extreme point satisfies the corresponding constraint; similarly, “-” indicates that the constraint is not satisfied. The results of all the constraints are summarized in Table 6 . 
TABLE 6

\begin{tabular}{lccc}
\hline$\theta$ & $\left(0, \bar{\theta}_{6}\right]$ & $\left(\bar{\theta}_{6}, \bar{\theta}_{5}\right]$ & $\left(\bar{\theta}_{5}, \bar{\theta}_{4}\right)$ \\
\hline L1 & + & + & - \\
\hline L2 & - & + & + \\
\hline L3 & + & + & + \\
\hline L6 & + & + & + \\
\hline $\bar{\theta}_{4}=2 \sqrt{2} / 3, \bar{\theta}_{5}$ & $=\left(-2 \alpha-5+\sqrt{100 \alpha^{2}+164 \alpha+73}\right) / 12(\alpha+1)$, and $\bar{\theta}_{6}=$ \\
$(-5+\sqrt{73}) / 12$. & &
\end{tabular}

We analyse the equilibrium solution of different parameter ranges and use $\left(w_{2}^{f}, p_{e, 2}^{f}\right)$ to denote the corresponding partial equilibrium solutions in R2.

Analysis 1 (if $\left\{0<\theta \leq \bar{\theta}_{6}\right\} \cap\{0<\alpha<1\}$ ). Based on Table 6 , only constraint (L2) is not satisfied, which implies that the partial equilibrium solution is on the boundary of L3. Combined with the results for (2) of Appendix B.1, we can infer the corresponding partial equilibrium solution in this situation:

$$
\left(w_{2}^{f}, p_{e, 2}^{f}\right)=\left(\bar{w}_{2,2}^{f *}, \bar{p}_{e, 2,2}^{f *}\right)
$$

Analysis 2 (if $\left\{\bar{\theta}_{6}<\theta \leq \bar{\theta}_{5}\right\} \cap\{0<\alpha<1\}$ ). Based on Table 5, all the constraints are satisfied, which implies that the extreme point is the partial equilibrium solution.

$$
\left(w_{2}^{f}, p_{e, 2}^{f}\right)=\left(w_{2}^{f *}, p_{e, 2}^{f *}\right) .
$$

Analysis 3 (if $\left\{\bar{\theta}_{5}<\theta<\bar{\theta}_{4}\right\} \cap\{0<\alpha<1\}$ ). Based on Table 6, only constraint (L1) is not satisfied, which implies that the partial equilibrium solution is on the boundary of
L1. Combined with the result of Appendix B.1 (1), we can infer the corresponding partial equilibrium solution in this situation:

$$
\left(w_{2}^{f}, p_{e, 2}^{f}\right)=\left(\bar{w}_{2,1}^{f *}, \bar{p}_{e, 2,1}^{f *}\right)
$$

\section{B.3. Inferring the Partial Equilibrium Solution When $0<\boldsymbol{\theta}<\overline{\boldsymbol{\theta}}_{4}$}

Analysis 4 (if $\left\{\bar{\theta}_{4} \leq \theta<1\right\} \cap\{0<\alpha<1\}$ ). Similarly, with R1, we should determine and compare the optimal solutions for L1, L2, L3, and L4.

(1)

$$
\begin{aligned}
& \alpha \in(0,1), \\
& \frac{2 \sqrt{2}}{3}>\frac{\sqrt{2(\alpha+1)(2 \alpha+1)}}{2(\alpha+1)}, \\
& \frac{2 \sqrt{2}}{3}>\frac{\alpha}{2(\alpha+1)} .
\end{aligned}
$$

(2)

$$
\begin{aligned}
\pi_{m \cdot 2}\left(\bar{w}_{2,3}, \bar{p}_{e 2,3}\right) & =\pi_{m \cdot 2}\left(w_{C}, p_{e, C}\right) \\
& <\pi_{m \cdot 2}\left(\bar{w}_{2,3}^{*}, \bar{p}_{e 2,3}^{*}\right) .
\end{aligned}
$$

$$
\begin{aligned}
\pi_{m \cdot 2}\left(\bar{w}_{2,6}, \bar{p}_{e 2,6}\right) & =\pi_{m \cdot 2}\left(w_{A}, p_{e, A}\right) \\
& <\pi_{m \cdot 2}\left(\bar{w}_{2,3}^{*}, \bar{p}_{e 2,3}^{*}\right) .
\end{aligned}
$$

(4)

$$
\pi_{m .2}\left(\bar{w}_{2,1}^{*}, \bar{p}_{e 2,1}^{*}\right)-\pi_{m .2}\left(\bar{w}_{2,2}^{*}, \bar{p}_{e 2,2}^{*}\right)=\frac{(\theta c+a-c)^{2} \alpha\left((\alpha+1)\left(12 \theta^{4}-8 \theta^{3}-44 \theta^{2}-8 \theta+16\right)-11 \theta^{2}-16 \theta-4\right)}{112\left(\left(\alpha^{2}+(11 / 4) \alpha+7 / 4\right) \theta^{2}-(\alpha+3 / 2)^{2}\right)\left(9 / 7-\theta^{2}\right)}>0 .
$$
is

Combined with (1)-(4), the partial equilibrium solution

$$
\left(w_{2}^{f}, p_{e, 2}^{f}\right)=\left(\bar{w}_{2,1}^{f *}, \bar{p}_{e 2,1}^{f *}\right) .
$$

To summarize Analyses 1-4, we can obtain the partial equilibrium solution set in region $\mathrm{R} 2$, which are shown in Table 3.

\section{Proof of Lemma 4}

The manufacturer's problem in $\mathrm{R} 3$ is

$$
\begin{aligned}
\max _{p_{e}, w} & \pi_{m 3}^{f}=d_{e}\left(p_{e}-c\right)+d_{r}(w-c) \\
\text { s.t } & p_{r}=\frac{\theta p_{e}+w+a}{2}, \\
& p_{e} \geq K_{2} w-D_{2},
\end{aligned}
$$

$$
\begin{aligned}
& p_{e} \geq K_{3} w-D_{3}, \\
& p_{e} \leq K_{7} w-D_{7}, \\
& w>c
\end{aligned}
$$

The Hessian matrix $H_{\pi_{m}}\left[\begin{array}{l}p_{e} \\ w\end{array}\right]$ is negative definite. The manufacturer's profit function is a concave function of $p_{e}$ and $w$, and the decision problem is a convex optimization problem. Thus, a unique extreme point exists as follows:

$$
p_{e, 3}^{f *}=w_{3}^{f *}=\frac{a}{2(1-\theta)}+\frac{c}{2}
$$

Analysis 1. If $\left(w_{3}^{f *}, p_{e, 3}^{f *}\right)$ is brought into each boundary, then only L2 is not satisfied. Thus, we can deduce that the partial equilibrium solution of R3 is on L2. The optimal point for the 
L2 of R2 and R3 is the same. Combined with Appendix B.1, the partial equilibrium solution is

$$
\left(w_{3}^{f}, p_{e, 3}^{f}\right)=\left(\bar{w}_{3,2}^{f *}, \bar{p}_{e, 3,2}^{f *}\right)=\left(\bar{w}_{2,2}^{f *}, \bar{p}_{e, 2,2}^{f *}\right) .
$$

\section{Proof of Proposition 5}

We have obtained the partial equilibrium solution set of R1, $\mathrm{R} 2$, and R3. The manufacturer would compare the solutions for the different regions that are in the same parameter range and choose the optimum solution as the equilibrium pricing strategy. The process of inference is as follows:

(1) By comparing the different thresholds in Lemmas 2-4, we can divide the parameter ranges that the solution needs to compare. This part is given in Appendix D.1.

(2) Based on the results of Appendix D.1, we determine the complete equilibrium solution. This part is given in Appendices D.2 and D.3.

D.1. Divide the Parameter Ranges That the Solution Needs to Compare. Combined with Lemmas 2, 3, and 4; the relevant thresholds are summarized as follows:

$$
\begin{aligned}
& \bar{\theta}_{1}=2 \sqrt{\frac{2\left(2 \alpha^{2}+3 \alpha+1\right)}{17 \alpha^{2}+24 \alpha+8}}, \\
& \bar{\theta}_{2} \\
& =\frac{-2 \alpha^{2}-7 \alpha-4+\sqrt{100 \alpha^{4}+204 \alpha^{3}+113 \alpha^{2}+8 \alpha}}{4\left(3 \alpha^{2}+4 \alpha+1\right)}, \\
& \bar{\theta}_{3}=\frac{2(\alpha+1)}{3 \alpha+2}, \\
& \bar{\theta}_{4}=\frac{2 \sqrt{2}}{3}, \\
& \bar{\theta}_{5}=\frac{-2 \alpha-5+\sqrt{100 \alpha^{2}+164 \alpha+73}}{12(\alpha+1)}, \\
& \bar{\theta}_{6}=\frac{-5+\sqrt{73}}{12}, \\
& \alpha_{1}=\frac{1}{2} .
\end{aligned}
$$

(1)

$$
\begin{gathered}
\max \left(\bar{\theta}_{3}, \bar{\theta}_{4}\right) \begin{cases}\bar{\theta}_{3} & 0<\alpha \leq \frac{3-2 \sqrt{2}}{3(\sqrt{2}-1)} \\
\bar{\theta}_{4} & \frac{3-2 \sqrt{2}}{3(\sqrt{2}-1)}<\alpha<1 ;\end{cases} \\
\max \left(\bar{\theta}_{2}, 0\right) \begin{cases}0 & 0<\alpha \leq \alpha_{1} \\
\bar{\theta}_{2} & \alpha<\alpha<1 .\end{cases}
\end{gathered}
$$

(2) $\bar{\theta}_{2}<\bar{\theta}_{6}<\bar{\theta}_{5}<\bar{\theta}_{1}<1 ; \bar{\theta}_{5}<\bar{\theta}_{4}<\bar{\theta}_{1} ; \bar{\theta}_{5}<\bar{\theta}_{4}<\bar{\theta}_{3}$. Combined with (1) and (2), we can conclude
TABLE 7

\begin{tabular}{lccccc}
\hline region & $\left(0, \bar{\theta}_{6}\right]$ & $\left(\bar{\theta}_{6}, \bar{\theta}_{5}\right]$ & $\left(\bar{\theta}_{5}, \bar{\theta}_{4}\right]$ & $\left(\bar{\theta}_{4}, \bar{\theta}_{3}\right)$ & {$\left[\bar{\theta}_{3}, 1\right)$} \\
\hline R1 & $w_{1}^{f *}, p_{e, 1}^{f *}$ & $w_{1}^{f *}, p_{e, 1}^{f *}$ & $w_{1}^{f *}, p_{e, 1}^{f *}$ & $w_{1}^{f *}, p_{e, 1}^{f *}$ & $\bar{w}_{1,4}^{f *}, \bar{p}_{e, 1,4}^{f *}$ \\
\hline R2 & $\bar{w}_{2,2}^{f *}, \bar{p}_{e, 2,2}^{f *}$ & $w_{2}^{f *}, p_{e, 2}^{f *}$ & $\bar{w}_{2,1}^{f *}, \bar{p}_{e, 2,1}^{f *}$ & $\bar{w}_{2,1}^{f *}, \bar{p}_{e, 2,1}^{f *}$ & $\bar{w}_{2,1}^{f *}, \bar{p}_{e, 2,1}^{f *}$ \\
\hline R3 & $\bar{w}_{3,2}^{f *}, \bar{p}_{e, 3,2}^{f *}$ & $\bar{w}_{3,2}^{f *}, \bar{p}_{e, 3,2}^{f *}$ & $\bar{w}_{3,2}^{f *}, \bar{p}_{e, 3,2}^{f *}$ & $\bar{w}_{3,2}^{f *}, \bar{p}_{e, 3,2}^{f *}$ & $\bar{w}_{3,2}^{f *}, \bar{p}_{e, 3,2}^{f *}$ \\
\hline
\end{tabular}

TABLE 8

\begin{tabular}{lccccc}
\hline region & $\left(0, \bar{\theta}_{6}\right]$ & $\left(\bar{\theta}_{6}, \bar{\theta}_{5}\right]$ & $\left(\bar{\theta}_{5}, \bar{\theta}_{3}\right)$ & {$\left[\bar{\theta}_{3}, \bar{\theta}_{4}\right)$} & {$\left[\bar{\theta}_{4}, 1\right)$} \\
\hline R1 & $w_{1}^{f *}, p_{e, 1}^{f *}$ & $w_{1}^{f *}, p_{e, 1}^{f *}$ & $w_{1}^{f *}, p_{e, 1}^{f *}$ & $\bar{w}_{1,4}^{f *}, \bar{p}_{e, 1,4}^{f *}$ & $\bar{w}_{1,4}^{f *}, \bar{p}_{e, 1,4}^{f *}$ \\
\hline R2 & $\bar{w}_{2,2}^{f *}, \bar{p}_{e, 2,2}^{f *}$ & $w_{2}^{f *}, p_{e, 2}^{f *}$ & $\bar{w}_{2,1}^{f *}, \bar{p}_{e, 2,1}^{f *}$ & $\bar{w}_{2,1}^{f *}, \bar{p}_{e, 2,1}^{f *}$ & $\bar{w}_{2,1}^{f *}, \bar{p}_{e, 2,1}^{f *}$ \\
\hline R3 & $\bar{w}_{3,2}^{f *}, \bar{p}_{e, 3,2}^{f *}$ & $\bar{w}_{3,2}^{f *}, \bar{p}_{e, 3,2}^{f *}$ & $\bar{w}_{3,2}^{f *}, \bar{p}_{e, 3,2}^{f *}$ & $\bar{w}_{3,2}^{f *}, \bar{p}_{e, 3,2}^{f *}$ & $\bar{w}_{3,2}^{f *}, \bar{p}_{e, 3,2}^{f *}$ \\
\hline
\end{tabular}

(3) if $0<\alpha \leq(3-2 \sqrt{2}) / 3(\sqrt{2}-1) \Longrightarrow 0<\bar{\theta}_{6}<\bar{\theta}_{5}<$ $\bar{\theta}_{4}<\bar{\theta}_{3}<\bar{\theta}_{1}<1$.

The problem of the manufacturer's decision is shown in Table 7:

(4) if $(3-2 \sqrt{2}) / 3(\sqrt{2}-1)<\alpha \leq \alpha_{1} \Longrightarrow 0<\bar{\theta}_{6}<\bar{\theta}_{5}<$ $\bar{\theta}_{3}<\bar{\theta}_{4}<\bar{\theta}_{1}<1$.

The problem of the manufacturer's decision is shown in Table 8:

(5) if $\alpha_{1}<\alpha<1 \Longrightarrow 0<\bar{\theta}_{2}<\bar{\theta}_{6}<\bar{\theta}_{5}<\bar{\theta}_{3}<\bar{\theta}_{4}<\bar{\theta}_{1}<$ 1.

The problem of the manufacturer's decision is shown in Table 9.

D.2. R3 and R2: Comparison of the Partial Equilibrium Solutions of $R 3$ and $R 2$

Analysis 1 (if $\left\{0<\theta \leq \bar{\theta}_{6}\right\} \cap\{0<\alpha<1\}$ ). As $\bar{w}_{3,2}^{f *}=\bar{w}_{2,2}^{f *}$, $\bar{p}_{e 3,2}^{f *}=\bar{p}_{e 2,2}^{f *}$, the partial equilibrium solutions of R3 and R2 are the same.

Analysis 2 (if $\left\{\bar{\theta}_{6}<\theta \leq \bar{\theta}_{5}\right\} \cap\{0<\alpha<1\}$ ). It is easy to prove that $\pi_{m .2}\left(w_{2}^{f *}, p_{e 2}^{f *}\right)-\pi_{m .3}\left(\bar{w}_{3,2}^{f *}, \bar{p}_{e 3,2}^{f *}\right)>0$. Thus, the partial equilibrium solutions of R2 are better than those for R3.

Analysis 3 (if $\left\{\bar{\theta}_{5}<\theta<1\right\} \cap\{0<\alpha<1\}$ ).

$$
\begin{aligned}
& \pi_{m .2}\left(\bar{w}_{2,1}^{f *}, \bar{p}_{e 2,1}^{f *}\right)-\pi_{m .2}\left(\bar{w}_{3,2}^{f *}, \bar{p}_{e 3,2}^{f *}\right) \\
& =\frac{(\theta c+a-c)^{2} \alpha(Y 5 \alpha+Y 6)}{112\left(\left(\alpha^{2}+(11 / 4) \alpha+7 / 4\right) \theta^{2}-(\alpha+3 / 2)^{2}\right)\left(9 / 7-\theta^{2}\right)}
\end{aligned}
$$

where $Y 5=12 \theta^{2}-8 \theta^{3}-44 \theta^{2}-8 \theta+16 ; Y 6=12 \theta^{2}-8 \theta^{3}-$ $55 \theta^{2}-24 \theta+12$. 
TABLE 9

\begin{tabular}{|c|c|c|c|c|c|c|}
\hline \multirow{2}{*}{ region } & \multicolumn{6}{|c|}{$\theta$} \\
\hline & $\left(0, \bar{\theta}_{2}\right]$ & $\left(\bar{\theta}_{2}, \bar{\theta}_{6}\right]$ & $\left(\bar{\theta}_{6}, \bar{\theta}_{5}\right]$ & $\left(\bar{\theta}_{5}, \bar{\theta}_{3}\right)$ & {$\left[\bar{\theta}_{3}, \bar{\theta}_{4}\right)$} & {$\left[\bar{\theta}_{4}, 1\right)$} \\
\hline $\mathrm{R} 1$ & $\bar{w}_{1,1}^{f *}, \bar{p}_{e, 1,1}^{f *}$ & $w_{1}^{f *}, p_{e, 1}^{f *}$ & $w_{1}^{f *}, p_{e, 1}^{f *}$ & $w_{1}^{f *}, p_{e, 1}^{f *}$ & $\bar{w}_{1,4}^{f *}, \bar{p}_{e, 1,4}^{f *}$ & $\bar{w}_{1,4}^{f *}, \bar{p}_{e, 1,4}^{f *}$ \\
\hline $\mathrm{R} 2$ & $\bar{w}_{2,2}^{f *}, \bar{p}_{e, 2,2}^{f *}$ & $\bar{w}_{2,2}^{f *}, \bar{p}_{e, 2,2}^{f *}$ & $w_{2}^{f *}, p_{e, 2}^{f *}$ & $\bar{w}_{2,1}^{f *}, \bar{p}_{e, 2,1}^{f *}$ & $\bar{w}_{2,1}^{f *}, \bar{p}_{e, 2,1}^{f *}$ & $\bar{w}_{2,1}^{f *}, \bar{p}_{e, 2,1}^{f *}$ \\
\hline R3 & $\bar{w}_{3,2}^{f *}, \bar{p}_{e, 3,2}^{f *}$ & $\bar{w}_{3,2}^{f *}, \bar{p}_{e, 3,2}^{f *}$ & $\bar{w}_{3,2}^{f *}, \bar{p}_{e, 3,2}^{f *}$ & $\bar{w}_{3,2}^{f *}, \bar{p}_{e, 3,2}^{f *}$ & $\bar{w}_{3,2}^{f *}, \bar{p}_{e, 3,2}^{f *}$ & $\bar{w}_{3,2}^{f *}, \bar{p}_{e, 3,2}^{f *}$ \\
\hline
\end{tabular}

TABle 10

\begin{tabular}{lcccc}
\hline region & $\left(0, \bar{\theta}_{6}\right]$ & $\left(\bar{\theta}_{6}, \bar{\theta}_{5}\right]$ & $\left(\bar{\theta}_{5}, \bar{\theta}_{3}\right]$ & $\left(\bar{\theta}_{3}, 1\right)$ \\
\hline R1 & $w_{1}^{f *}, p_{e, 1}^{f *}$ & $w_{1}^{f *}, p_{e, 1}^{f *}$ & $w_{1}^{f *}, p_{e, 1}^{f *}$ & $\bar{w}_{1,4}^{f *}, \bar{p}_{e, 1,4}^{f *}$ \\
\hline R2 & $\bar{w}_{2,2}^{f *}, \bar{p}_{e, 2,2}^{f *}$ & $w_{2}^{f *}, p_{e, 2}^{f *}$ & $\bar{w}_{2,1}^{f *}, \bar{p}_{e, 2,1}^{f *}$ & $\bar{w}_{2,1}^{f *}, \bar{p}_{e, 2,1}^{f *}$ \\
\hline
\end{tabular}

TABLE 11

\begin{tabular}{lccccc}
\hline region & $\left(0, \bar{\theta}_{2}\right]$ & $\left(\bar{\theta}_{2}, \bar{\theta}_{6}\right]$ & $\left(\bar{\theta}_{6}, \bar{\theta}_{5}\right]$ & $\left(\bar{\theta}_{5}, \bar{\theta}_{3}\right)$ & {$\left[\bar{\theta}_{3}, 1\right)$} \\
\hline R1 & $\bar{w}_{1,1}^{f *}, \bar{p}_{e, 1,1}^{f *}$ & $w_{1}^{f *}, p_{e, 1}^{f *}$ & $w_{1}^{f *}, p_{e, 1}^{f *}$ & $w_{1}^{f *}, p_{e, 1}^{f *}$ & $\bar{w}_{1,4}^{f *}, \bar{p}_{e, 1,4}^{f *}$ \\
\hline R2 & $\bar{w}_{2,2}^{f *}, \bar{p}_{e, 2,2}^{f *}$ & $\bar{w}_{2,2}^{f *}, \bar{p}_{e, 2,2}^{f *}$ & $w_{2}^{f *}, p_{e, 2}^{f *}$ & $\bar{w}_{2,1}^{f *}, \bar{p}_{e, 2,1}^{f *}$ & $\bar{w}_{2,1}^{f *}, \bar{p}_{e, 2,1}^{f *}$ \\
\hline
\end{tabular}

For all $\bar{\theta}_{5}<\theta<1$ and $0<\alpha<1$, we can prove that $\left(\alpha^{2}+(11 / 4) \alpha+7 / 4\right) \theta^{2}-(\alpha+3 / 2)^{2}<0, Y 1 \alpha+Y 2<0$. Therefore, we conclude that $\pi_{m .2}\left(\bar{w}_{2,1}^{f *}, \bar{p}_{e 2,1}^{f *}\right)>\pi_{m .2}\left(\bar{w}_{3,2}^{f *}, \bar{p}_{e 3,2}^{f *}\right)$. The manufacturer would choose the solution of R2.

Analysis 4. By combining Analysis 1-3, we find that the partial equilibrium solution of R2 is always more profitable than R3. Combined with Appendix D.1 (4)-(6), the problem of the manufacturer's decision can be simplified and is shown in Tables 10 and 11.

(1) If $0<\alpha \leq \alpha_{1}$. See Table 10 .

(2) If $\alpha_{1}<\alpha<1$. See Table 11 .
D.3. Comparison of the Equilibrium Solutions of $R 2$ and R1. By comparing the solutions of R2 and R3, the more profitable solutions are the final equilibrium solutions for the manufacturer and the retailer. We use $\left(w^{f * *}, p_{e}^{f * *}\right)$ to denote them. Based on Tables 10 and 11, the results are as follows.

Analysis 1. If $\left\{\left\{0<\theta \leq \bar{\theta}_{6}\right\} \cap\{0<\alpha \leq 1 / 2\}\right\} \cup\left\{\left\{\bar{\theta}_{2}<\theta \leq\right.\right.$ $\left.\left.\bar{\theta}_{6}\right\} \cap\{1 / 2<\alpha<1\}\right\}$, compare $\left(w_{1}^{f *}, p_{e 1}^{f *}\right)$ with $\left(\bar{w}_{2,2}^{f *}, \bar{p}_{e 2,2}^{f *}\right)$.

$$
\begin{aligned}
& \pi_{m .1}\left(w_{1}^{f *}, p_{e 1}^{f *}\right)-\pi_{m .2}\left(\bar{w}_{2,2}^{f *}, \bar{p}_{e 2,2}^{f *}\right) \\
& =\frac{(\theta c+a-c)^{2} \alpha\left(Y 7 \alpha^{2}+Y 8 \alpha+Y 9\right)}{\left(17 \theta^{2} \alpha^{2}+24 \theta^{2} \alpha+8 \theta^{2}-16 \alpha^{2}-24 \alpha-8\right)\left(7 \theta^{2}-9\right)}
\end{aligned}
$$

where

$$
\begin{aligned}
& Y 7=3 \theta^{4}+19 \theta^{3}+\frac{89}{4} \theta^{2}-\theta-7 \\
& Y 8=3 \theta^{4}+19 \theta^{3}+25 \theta^{2}+3 \theta-6 \\
& Y 9=\theta^{4}+4 \theta^{3}+6 \theta^{2}+4 \theta+1 .
\end{aligned}
$$

For all $0<\theta \leq \bar{\theta}_{6}, 17 \theta^{2} \alpha^{2}+24 \theta^{2} \alpha+8 \theta^{2}-16 \alpha^{2}-24 \alpha-8>0$, $Y 1<0$.

By making $Y 7 \alpha^{2}+Y 8 \alpha+Y 9=0$, we can obtain

$$
\begin{aligned}
& \alpha^{+}=\frac{-2(\theta+1)\left(3 \theta^{3}+16 \theta^{2}+9 \theta-6+\sqrt{-3 \theta^{6}-4 \theta^{5}+57 \theta^{4}+2 \theta^{3}-164 \theta^{2}-48 \theta+64}\right)}{12 \theta^{4}+76 \theta^{3}+89 \theta^{2}-4 \theta-28}, \\
& \alpha^{-}=\frac{-2(\theta+1)\left(3 \theta^{3}+16 \theta^{2}+9 \theta-6-\sqrt{-3 \theta^{6}-4 \theta^{5}+57 \theta^{4}+2 \theta^{3}-164 \theta^{2}-48 \theta+64}\right)}{12 \theta^{4}+76 \theta^{3}+89 \theta^{2}-4 \theta-28} .
\end{aligned}
$$

(1) If $0<\alpha \leq \alpha^{+}, \pi_{m .1}\left(w_{1}^{f *}, p_{e 1}^{f *}\right)-\pi_{m .2}\left(\bar{w}_{2,2}^{f *}, \bar{p}_{e, 2,2}^{f *}\right)>0$; if $\alpha^{+}<\alpha<1, \pi_{m .1}\left(w_{1}^{f *}, p_{e 1}^{f *}\right)-\pi_{m .2}\left(\bar{w}_{2,2}^{f *}, \bar{p}_{e, 2,2}^{f *}\right)<0$.

We make $\alpha_{2}=\alpha^{+}$. We need to compare the size of $\alpha_{2}$ and $\alpha_{1}$.

$$
\max \left(\alpha_{2}, \alpha_{1}\right) \begin{cases}\alpha_{2} & \text { if } 0<\theta<\bar{\theta}_{2} \\ \alpha_{1} & \text { if } \theta=\bar{\theta}_{6}\end{cases}
$$

$\left(\alpha_{2}-\alpha_{1}\right)$ is a monotone increasing function of $\theta$. There exists a threshold $\bar{\theta}_{7}\left(\bar{\theta}_{7} \in\left(\bar{\theta}_{2}, \bar{\theta}_{6}\right)\right)$. If $\theta \in\left(0, \bar{\theta}_{7}\right), \alpha_{2}<\alpha_{1}$; if $\theta \in\left[\bar{\theta}_{7}, \bar{\theta}_{6}\right), \alpha_{1} \leq \alpha_{2}<1$.

Solution 1 of Analysis 1: If $\left\{0<\theta \leq \bar{\theta}_{6}\right\} \cap\left\{0<\alpha \leq \alpha_{1}\right\}$. Simultaneously, $0<\theta \leq \bar{\theta}_{7}, 0<\alpha \leq \alpha_{2}$, and $\pi_{m .1}\left(w_{1}^{f *}, p_{e 1}^{f *}\right)-$ $\pi_{m .2}\left(\bar{w}_{2,2}^{f *}, \bar{p}_{e 2,2}^{f *}\right) \geq 0$; the equilibrium solution is

$$
\left(w^{f * *}, p_{e}^{f * *}\right)=\left(w_{1}^{f *}, p_{e, 1}^{f *}\right)
$$


Simultaneously, $0<\theta \leq \bar{\theta}_{7}, \alpha_{2}<\alpha \leq \alpha_{1}$, and $\pi_{m .1}\left(w_{1}^{f *}, p_{e 1}^{f *}\right)-\pi_{m .2}\left(\bar{w}_{2,2}^{f *}, \bar{p}_{e 2,2}^{f *}\right) \leq 0$; the equilibrium solution is

$$
\left(w^{f * *}, p_{e}^{f * *}\right)=\left(\bar{w}_{2,2}^{f *}, \bar{p}_{e, 2,2}^{f *}\right)
$$

Simultaneously, $\bar{\theta}_{7}<\theta \leq \bar{\theta}_{6}, 0<\alpha \leq \alpha_{2}$, and $\pi_{m .1}\left(w_{1}^{f *}, p_{e 1}^{f *}\right)-\pi_{m .2}\left(\bar{w}_{2,2}^{f *}, \bar{p}_{e 2,2}^{f *}\right) \geq 0$; the equilibrium solution is

$$
\left(w^{f * *}, p_{e}^{f * *}\right)=\left(w_{1}^{f *}, p_{e, 1}^{f *}\right)
$$

Solution 2 of Analysis 1: If $\left\{\bar{\theta}_{2}<\theta \leq \bar{\theta}_{6}\right\} \cap\left\{\alpha_{1}<\alpha<1\right\}$. Simultaneously, $\bar{\theta}_{2}<\theta \leq \bar{\theta}_{7}, \alpha_{1}<\alpha<1$, and $\pi_{m .1}\left(w_{1}^{f *}, p_{e 1}^{f *}\right)-$ $\pi_{m .2}\left(\bar{w}_{2,2}^{f *}, \bar{p}_{e 2,2}^{f *}\right)<0$; the equilibrium solution is

$$
\left(w^{f * *}, p_{e}^{f * *}\right)=\left(\bar{w}_{2,2}^{f *}, \bar{p}_{e, 2,2}^{f *}\right)
$$

Simultaneously, $\bar{\theta}_{7}<\theta \leq \bar{\theta}_{6}, \alpha_{1}<\alpha \leq \alpha_{2}$; $\pi_{m .1}\left(w_{1}^{f *}, p_{e, 1}^{f *}\right)-\pi_{m .2}\left(\bar{w}_{2,2}^{f *}, \bar{p}_{e 2,2}^{f *}\right) \geq 0$; the equilibrium solution is

$$
\left(w^{f * *}, p_{e}^{f * *}\right)=\left(w_{1}^{f *}, p_{e, 1}^{f *}\right)
$$

Simultaneously, $\bar{\theta}_{7}<\theta \leq \bar{\theta}_{6}, \alpha_{2}<\alpha<1$, and $\pi_{m .1}\left(w_{1}^{f *}, p_{e, 1}^{f *}\right)-\pi_{m .2}\left(\bar{w}_{2,2}^{f *}, \bar{p}_{e 2,2}^{f *}\right)<0$; the equilibrium solution is

$$
\left(w^{f * *}, p_{e}^{f * *}\right)=\left(\bar{w}_{2,2}^{f *}, \bar{p}_{e, 2,2}^{f *}\right)
$$

Analysis 2. If $\left\{0<\theta \leq \bar{\theta}_{2}\right\} \cap\left\{\alpha_{1}<\alpha<1\right\}$, then compare $\left(\bar{w}_{1,1}^{f *}, \bar{p}_{e 1,1}^{f *}\right)$ with $\left(\bar{w}_{2,2}^{f *}, \bar{p}_{e 2,2}^{f *}\right)$.

Solution of Analysis 2. It is easy to prove that $\pi_{m .1}\left(\bar{w}_{1,1}^{f *}, \bar{p}_{e 1,1}^{f *}\right)-$ $\pi_{m .2}\left(\bar{w}_{2,2}^{f *}, \bar{p}_{e 2,2}^{f *}\right)<0$; the equilibrium solution is

$$
\left(w^{f * *}, p_{e}^{f * *}\right)=\left(\bar{w}_{2,2}^{f *}, \bar{p}_{e, 2,2}^{f *}\right)
$$

Analysis 3. If $\left\{\bar{\theta}_{6}<\theta \leq \bar{\theta}_{5}\right\} \cap\{0<\alpha<1\}$, compare $\left(w_{1}^{f *}, p_{e, 1}^{f *}\right)$ with $\left(w_{2}^{f *}, p_{e, 2}^{f *}\right)$.

$$
\begin{aligned}
& \pi_{m .1}\left(w_{1}^{f *}, p_{e, 1}^{f *}\right)-\pi_{m .2}\left(w_{2}^{f *}, p_{e, 2}^{f *}\right) \\
& =\frac{(\theta c+a-c)^{2}(\theta+1)\left(Y 10 \alpha^{2}+Y 11 \alpha+Y 12\right)}{\left(17 \theta^{2} \alpha^{2}+24 \theta^{2} \alpha+8 \theta^{2}-16 \alpha^{2}-24 \alpha-8\right)\left(8-9 \theta^{2}\right)}
\end{aligned}
$$

where

$$
\begin{aligned}
& Y 10=18 \theta^{3}-6 \theta^{2}-16 \theta+8 \\
& Y 11=27 \theta^{3}-24 \theta+8 ; \\
& Y 12=9 \theta^{3}+3 \theta^{2}-8 \theta .
\end{aligned}
$$

It is easy to prove that $Y 10>0$ under this condition. By making $Y 10 \alpha^{2}+Y 11 \alpha+Y 12$ equal to zero, we can obtain

$$
\begin{aligned}
& \alpha^{+} \\
& =\frac{-9 \theta^{2}-6 \theta+4+\sqrt{9 \theta^{4}+12 \theta^{3}+4 \theta^{2}+16 \theta+16}}{(\theta+1)(3 \theta-2)},
\end{aligned}
$$

$\alpha$

$$
=\frac{-9 \theta^{2}-6 \theta+4-\sqrt{9 \theta^{4}+12 \theta^{3}+4 \theta^{2}+16 \theta+16}}{(\theta+1)(3 \theta-2)} .
$$

Make $\alpha_{3}=\alpha^{+}$; for all $\bar{\theta}_{6}<\theta \leq \bar{\theta}_{5}, \alpha_{3}>0$.

(1) If $0<\alpha \leq \alpha_{3}$, then $\pi_{m .1}\left(w_{1}^{f *}, p_{e, 1}^{f *}\right)-\pi_{m .2}\left(w_{2}^{f *}, p_{e, 2}^{f *}\right) \leq$ 0.

If $\alpha_{3}<\alpha$, then $\pi_{m .1}\left(w_{1}^{f *}, p_{e, 1}^{f *}\right)-\pi_{m .2}\left(w_{2}^{f *}, p_{e, 2}^{f *}\right)>0$.

(2) There exists a threshold $\bar{\theta}_{8} \in\left(\bar{\theta}_{6}, \bar{\theta}_{5}\right)$; if $\bar{\theta}_{6}<\theta \leq \bar{\theta}_{8}$, $\alpha_{3}<1$; if $\bar{\theta}_{8}<\theta \leq \bar{\theta}_{5}, \alpha_{3}>1$.

Solution of Analysis 3. $\bar{\theta}_{6}<\theta \leq \bar{\theta}_{5} ; 0<\alpha<1$. Simultaneously, $\bar{\theta}_{6}<\theta \leq \bar{\theta}_{8}, 0<\alpha \leq \alpha_{3}$, and $\pi_{m .1}\left(w_{1}^{f *}, p_{e, 1}^{f *}\right)-$ $\pi_{m .2}\left(w_{2}^{f *}, p_{e, 2}^{f *}\right) \geq 0$; the equilibrium solution is

$$
\left(w^{f * *}, p_{e}^{f * *}\right)=\left(w_{1}^{f *}, p_{e, 1}^{f *}\right)
$$

Simultaneously, $\bar{\theta}_{6}<\theta \leq \bar{\theta}_{8}, \alpha_{3}<\alpha<1$, and $\pi_{m .1}\left(w_{1}^{f *}, p_{e, 1}^{f *}\right)-\pi_{m .2}\left(w_{2}^{f *}, p_{e, 2}^{f *}\right)<0$; the equilibrium solution is

$$
\left(w^{f * *}, p_{e}^{f * *}\right)=\left(w_{2}^{f *}, p_{e, 2}^{f *}\right)
$$

Simultaneously, $\bar{\theta}_{8}<\theta \leq \bar{\theta}_{5}, 0<\alpha<1$, and $\pi_{m .1}\left(w_{1}^{f *}, p_{e, 1}^{f *}\right)-\pi_{m .2}\left(w_{2}^{f *}, p_{e, 2}^{f *}\right)>0$; the equilibrium solution is

$$
\left(w^{f * *}, p_{e}^{f * *}\right)=\left(w_{1}^{f *}, p_{e, 1}^{f *}\right)
$$

Analysis 4. If $\left\{\bar{\theta}_{5}<\theta \leq \bar{\theta}_{3}\right\} \cap\{0<\alpha<1\}$, then compare $\left(w_{1}^{f *}, p_{e, 1}^{f *}\right)$ with $\left(w_{2,1}^{f *}, p_{e 2,1}^{f *}\right)$.

Solution of Analysis 4: $\bar{\theta}_{5}<\theta \leq \bar{\theta}_{3} ; 0<\alpha<1$. $\pi_{m .1}\left(w_{1}^{f *}, p_{e, 1}^{f *}\right)>\pi_{m .2}\left(\bar{w}_{2,1}^{f *}, \bar{p}_{e, 2,1}^{f *}\right)$; the equilibrium solution is

$$
\left(w^{f * *}, p_{e}^{f * *}\right)=\left(w_{1}^{f *}, p_{e, 1}^{f *}\right)
$$

Analysis 5. If $\left\{\bar{\theta}_{3}<\theta<1\right\} \cap\{0<\alpha<1\}$, then compare $\left(\bar{w}_{1,4}^{f *}, \bar{p}_{e 1,4}^{f *}\right)$ with $\left(\bar{w}_{2,1}^{f *}, \bar{p}_{e 2,1}^{f *}\right)$.

Solution of Analysis 5. $\pi_{m .1}\left(\bar{w}_{1,4}^{f *}, \bar{p}_{e 1,4}^{f *}\right)-\pi_{m .2}\left(\bar{w}_{2,1}^{f *}, \bar{p}_{e 2,1}^{f *}\right)>0$; the equilibrium solution is

$$
\left(w^{f * *}, p_{e}^{f * *}\right)=\left(\bar{w}_{1,4}^{f *}, \bar{p}_{e 1,4}^{f *}\right)
$$

We have summarized (E1)-(E12), and the complete equilibrium solutions are shown in Table 4. 


\section{Data Availability}

The numerical experiment in this paper is mainly based on the inferred conclusion in this paper, and the corresponding parameter assignment is explained at the beginning of Section 5. Parameter setting mainly refers to the parameter setting of other similar studies, and references have been cited in this paper.

\section{Disclosure}

We declare that the work presented in this manuscript represents our original research that has not been published previously and is not under consideration for publication elsewhere, in whole or in part.

\section{Conflicts of Interest}

No conflicts of interest exit in the submission of this manuscript, which is approved by all authors for publication.

\section{References}

[1] K. Takahashi, T. Aoi, D. Hirotani, and K. Morikawa, "Inventory control in a two-echelon dual-channel supply chain with setup of production and delivery," International Journal of Production Economics, vol. 133, no. 2, pp. 403-415, 2011.

[2] "Accenture-Consumers-In-The-New-Full-Report-Chinese," 2018, https://www.accenture.com/cn-zh/insight-consumersin-the-new.

[3] http://www.camia.cn/content/775.html.

[4] M. Rabin, "Incorporating fairness into game theory and economics," The American Economic Review, vol. 83, no. 5, pp. 12811302, 1993.

[5] E. Fehr and K. M. Schmidt, "A theory of fairness, competition, and co-operation," The Quarterly Journal of Economics, vol. 114, no. 3, pp. 817-868, 1999.

[6] D. Kahneman, J. L. Knetsch, and R. H. Thaler, "Fairness and the assumptions of economics," Journal of Business, vol. 59, no. 4, pp. S285-S300, 1986.

[7] N. Kumar and L. K. Scheer, "The effects of supplier fairness on vulnerable resellers," Journal of Marketing Research, vol. 32, no. 1, pp. 54-65, 1995.

[8] D. Zhao, "Game analysis on vertical monopoly based on fixed resale minimum price-Take the case of Moutai and Wuliangy," Times Finance, no. 3, pp. 88-89, 2016.

[9] C. Xing, "Direct stores: game chips between Moutai and dealers," Wine World, no. 4, pp. 26-27, 2012.

[10] X. Zhong, "The delicate strategic partnership in supply chain management - inspiration of Gome and Gree marketing war," China Collective Economy, no. 05, p. 50, 2007.

[11] W. K. Chiang, D. Chhajed, and J. D. Hess, "Direct marketing, indirect profits: a strategic analysis of dual channel design," Management Science, vol. 49, no. 1, pp. 1-20, 2003.

[12] G. Ya-jun and Z. Li-qiang, "The conflict and coordination in dual channel based on e-market," System Engineering Theory and Practice, vol. 28, no. 9, pp. 59-66, 2008.

[13] K. Cattani, W. Gilland, H. S. Heese, and J. Swaminathan, "Boiling frogs: pricing strategies for a manufacturer adding a direct channel that competes with the traditional channel,"
Production Engineering Research and Development, vol. 15, no. 1, pp. 40-56, 2006.

[14] Q. Fang, L. Ren, and Y. Wang, "Pricing strategy of retailer dualchannel supply chain considering predominant power," Journal of Wuhan University of Science and Technology, vol. 40, no. 4, pp. 302-306, 2017.

[15] R. Yan and Z. Pei, "Retail services and firm profit in a dualchannel market," Journal of Retailing and Consumer Services, vol. 16, no. 4, pp. 306-314, 2009.

[16] J. F. Tian, T. J. Fan, and J. L. Hu, "Pricing policies in a dualchannel supply chain with manufacture services," in Proceedings of the International Conference on Computer Information Systems \& Industrial Applications, 2015.

[17] Q. Xu, Z. Liu, and B. Shen, "The impact of price comparison service on pricing strategy in a dual-channel supply chain," Mathematical Problems in Engineering, vol. 2013, Article ID 613528, 13 pages, 2013.

[18] C. Shen, Z. Xiong, and W. Yan, "Research on dual channel pricing and coordination strategy under the network price comparison," Chinese Journal of Management Science, vol. 22, no. 1, pp. 84-93, 2014.

[19] B. Li, M. Zhu, Y. Jiang, and Z. Li, "Pricing policies of a competitive dual-channel green supply chain," Journal of Cleaner Production, vol. 112, Part 3, pp. 2029-2042, 2016.

[20] F. Zhang and J. Ma, "Research on the complex features about a dual-channel supply chain with a fair caring retailer," Communications in Nonlinear Science and Numerical Simulation, vol. 30, no. 1-3, pp. 151-167, 2016.

[21] F. Zhang and C. Wang, "Dynamic pricing strategy and coordination in a dual-channel supply chain considering service value," Applied Mathematical Modelling: Simulation and Computation for Engineering and Environmental Systems, vol. 54, pp. 722-742, 2018.

[22] B. Dan, G. Y. Xu, and C. Liu, "Pricing policies in a dualchannel supply chain with retail services," International Journal of Production Economics, vol. 139, no. 1, pp. 312-320, 2012.

[23] Z. Ding, Research on The Pricing Strategy and Coordination Contracts of Dual Channel Supply Chain, Hefei University of Technology, 2015.

[24] J. Zhao, X. Hou, Y. Guo, and J. Wei, "Pricing policies for complementary products in a dual-channel supply chain," Applied Mathematical Modelling: Simulation and Computation for Engineering and Environmental Systems, vol. 49, pp. 437-451, 2017.

[25] J. Lin and J. Wang, "Research of manufacturers' channel strategy under dual-channel supply chain based on differentiated product," Chinese Journal of Management Science, vol. 26, no. 6, pp. 72-84, 2018.

[26] Y. Qu, Z. Guan, R. Qu, and T. Ye, “Impact of members' fairness preference and loss-averse on order strategy in hybrid dual channel supply chain," Chinese Journal of Management, vol. 14, no. 01, pp. 129-138, 2017.

[27] X. Wei, Q. Lin, and Y. Qin, "Optimal pricing strategies of dual-channel supply chain under risk aversion and fairness preference," Journal of Chongqing University of Technology (Social Science), vol. 30, no. 12, pp. 50-58, 2016.

[28] T. Nie and S. Du, "Dual-fairness supply chain with quantity discount contracts," European Journal of Operational Research, vol. 258, no. 2, pp. 491-500, 2017.

[29] Q.-H. Li and B. Li, "Dual-channel supply chain equilibrium problems regarding retail services and fairness concerns," Applied Mathematical Modelling, 2016. 
[30] F. Xu, R. Chuge, and W. Fan, "Impact of horizontal fairness and vertical fairness on strategies in dual-channel supply chain," Journal of Engineering System, vol. 29, no. 04, pp. 527-536, 2014.

[31] L. Wang, K. Cheng, and W. Shiwei, "Study on pricing strategies of dual-channel supply chain under fairness preference," Chinese Journal of Management Scinece, vol. 20, no. S2, pp. 563-568, 2012.

[32] B. Li, Y. Li, L. Hou, and P. Hou, "Impact of fair-minded retailer on decision of supply chain in dual- channel," Control and Decision, vol. 30, no. 05, pp. 955-960, 2015.

[33] X. Yue and J. Liu, "Demand forecast sharing in a dual-channel supply chain," European Journal of Operational Research, vol. 174, no. 1, pp. 646-667, 2006.

[34] S. Huang, C. Yang, and H. Liu, "Pricing and production decisions in a dual-channel supply chain when production costs are disrupted," Economic Modelling, vol. 30, no. 1, pp. 521-538, 2013.

[35] G. Y. Xu, B. Dan, X. M. Zhang, and C. Liu, "Coordinating a dual-channel supply chain with risk-averse under a two-way revenue sharing contract," International Journal of Production Economics, vol. 147, no. 1, pp. 171-179, 2014.

[36] W. Wang, L. Bo, N. Liao, and L. Xu, "Redefining customer experience in the new retail era- McKinsey China digital consumer research," Science and Technology of China, vol. 2017, no. 09, pp. 24-28, 2017.

[37] Niuli, Trends in Cosmetics Sales: Online and Offline Occupy Equal Shares, 2017, http://www.China.china.Chinairn.com/ hyzx/20170109/140751848.shtml.

[38] M. Liu, E. Cao, C. K. Salifou et al., "Pricing strategies of a dual-channel supply chain with risk aversion," Transportation Research Part E: Logistics and Transportation Review, vol. 90, pp. 108-120, 2016.

[39] C. Yuan, L. Yan, and G. Chai, "A dual-channel cournot game model with remarks on the policy of equal prices on the two channels of suning," Forecasting, vol. 33, no. 05, pp. 65-70, 2014.

[40] G. Charness and M. Rabin, "Understanding social preferences with simple tests," The Quarterly Journal of Economics, vol. 117, no. 3, pp. 817-869, 2002.

[41] G. F. Loewenstein, L. Thompson, and M. H. Bazerman, "Social utility and decision making in interpersonal contexts," Journal of Personality and Social Psychology, vol. 57, no. 3, pp. 426-441, 1989.

[42] T.-H. Ho and X. Su, "Peer-induced fairness in games," American Economic Review, vol. 99, no. 5, pp. 2022-2049, 2009.

[43] V. Pavlov and E. Katok, Fairness and Coordination Failures in Supply Chain Contracts. Working Paper, University of Texas at Dalls, 2009, http://www.utdallas.edu/ ekatok/fair_theory.pdf.

[44] X. Kong, "KUKA: Online and offline integration," China Chain Store, no. 10, pp. 52-53, 2015.

[45] J. Guo, "OPPO and Vivo: Mobile phone marketing strategy analysis," Modern SOE Research, no. 02, p. 96, 2018.

[46] http://www.sohu.com/a/128912758_121344. 


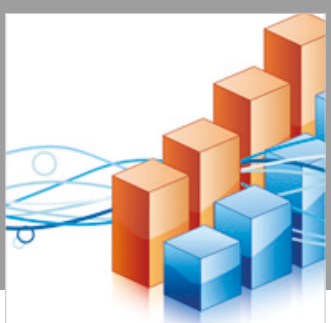

Advances in

Operations Research

\section{-n-m}
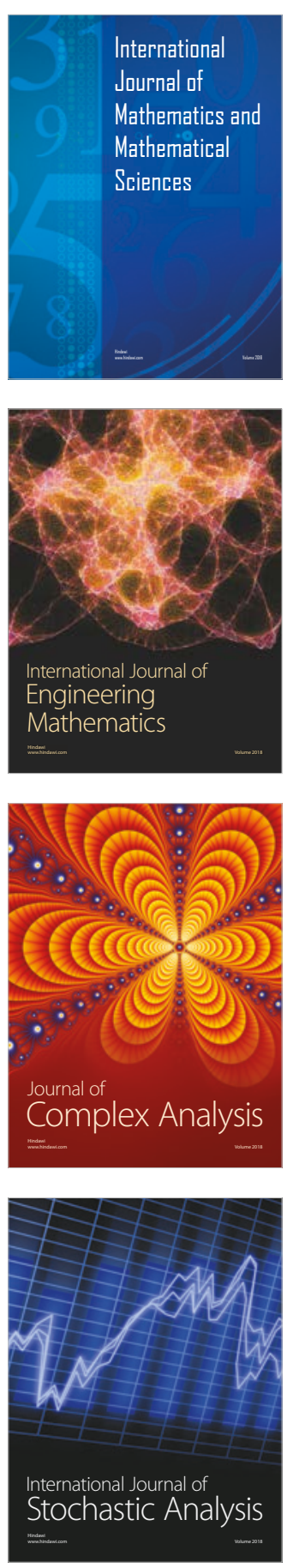
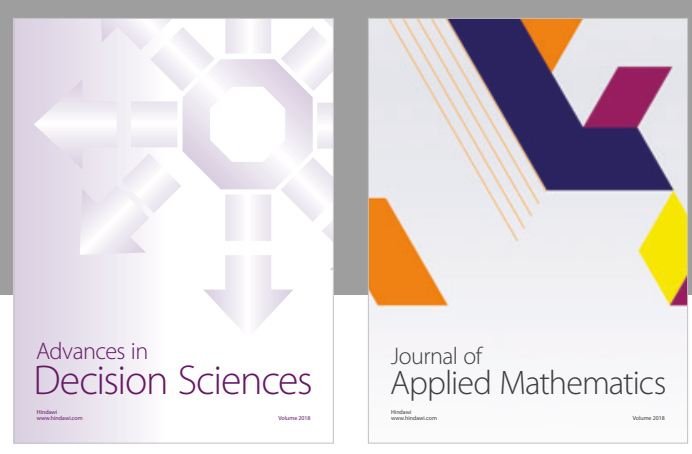

Journal of

Applied Mathematics
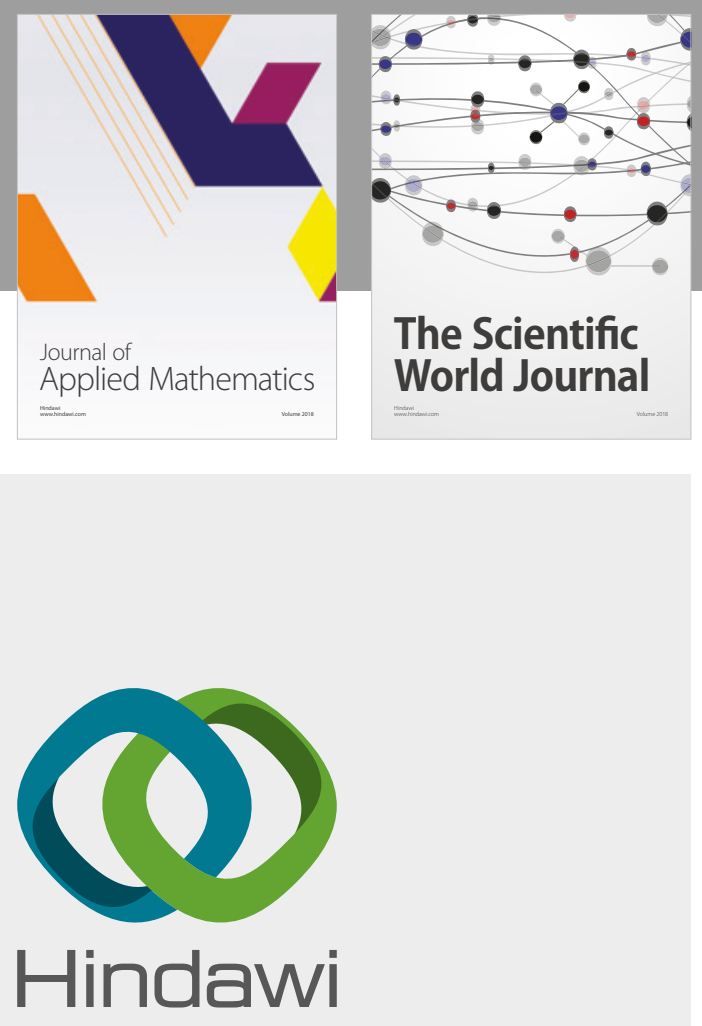

Submit your manuscripts at

www.hindawi.com

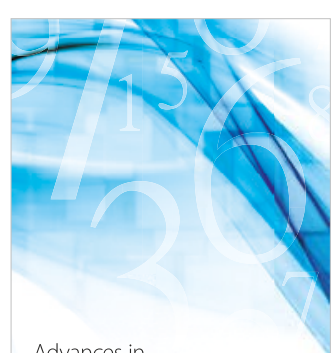

Advances in
Numerical Analysis
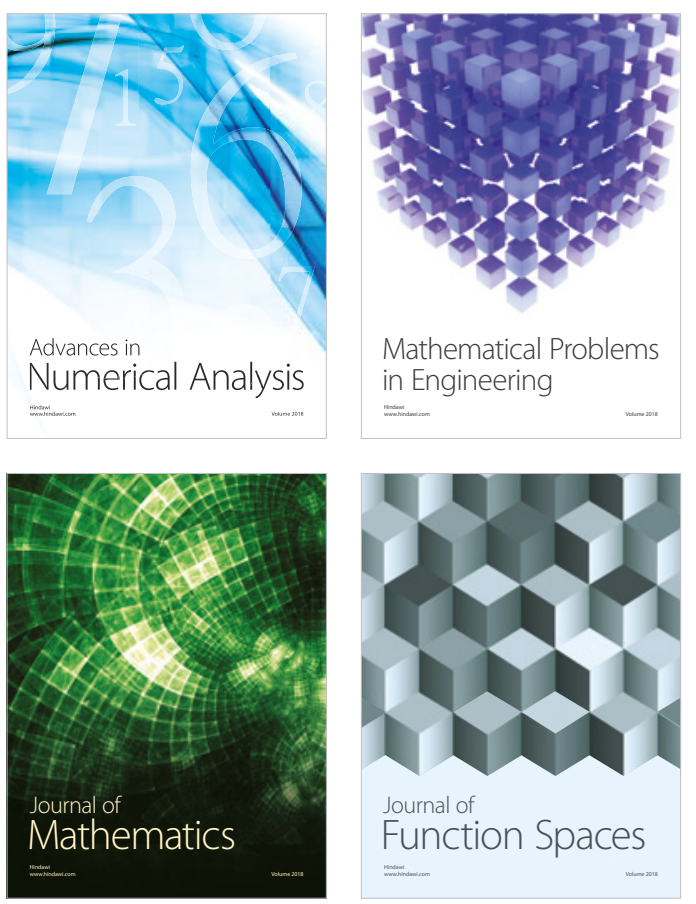

Mathematical Problems in Engineering

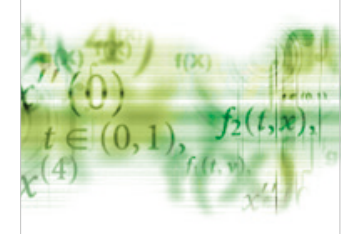

International Journal of

Differential Equations

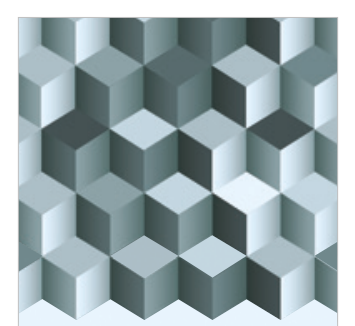

Journal of

Function Spaces
The Scientific

World Journal

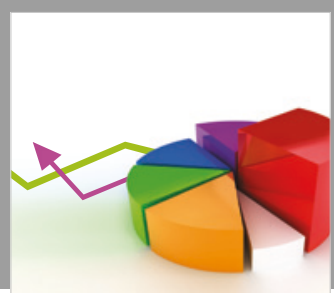

Journal of

Probability and Statistics
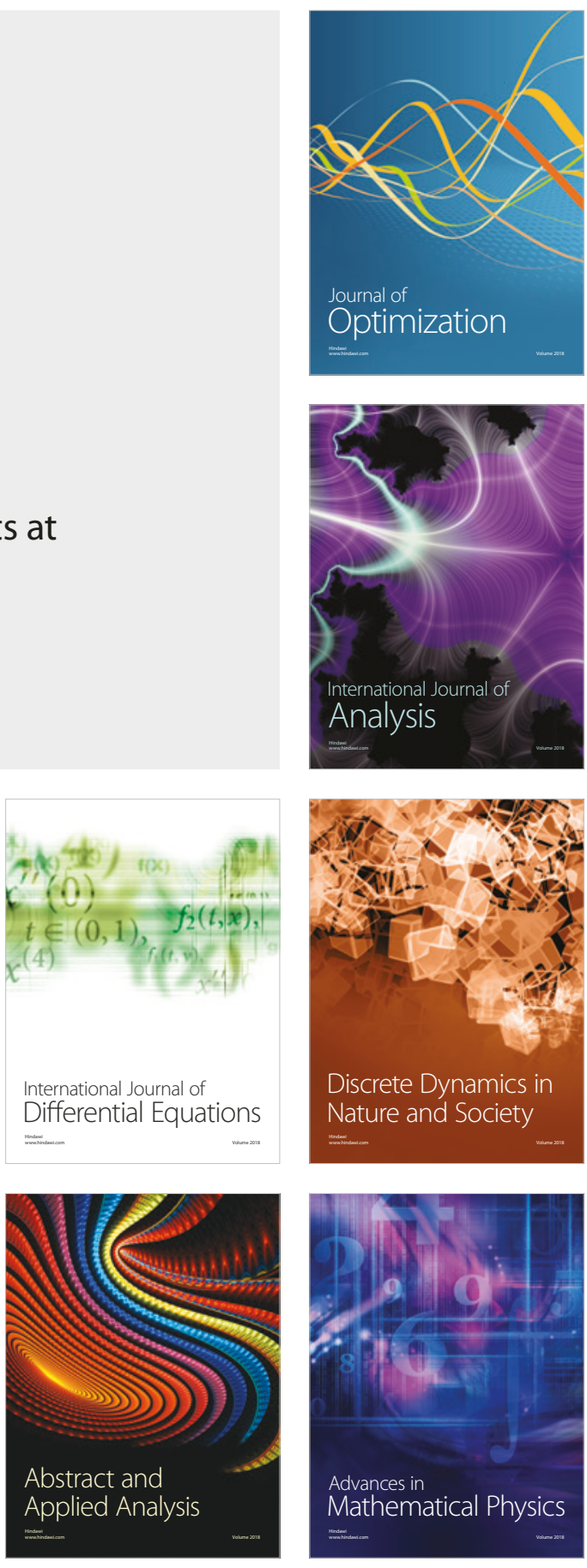